\title{
Role of Extracellular Trap Release During Bacterial and Viral Infection
}

\section{OPEN ACCESS}

Edited by:

Caterina Guzmán-Verri,

National University of Costa Rica,

Costa Rica

Reviewed by:

Marcin Zawrotniak,

Jagiellonian University, Poland

Luis A. Castillo,

Consejo Nacional de Investigaciones

Cientificas y Técnicas (CONICET),

Argentina

Ronald Anderson,

University of Pretoria, South Africa Stavros Giaglis,

University of Basel, Switzerland

*Correspondence:

Susan M. Bueno

sbueno@bio.puc.cl

Specialty section:

This article was submitted to Infectious Agents and Disease,

a section of the journal

Frontiers in Microbiology

Received: 20 October 2021 Accepted: 04 January 2022

Published: 26 January 2022

Citation:

Schultz BM, Acevedo OA Kalergis AM and Bueno SM (2022) Role of Extracellular Trap Release During Bacterial and Viral Infection.

Front. Microbiol. 13:798853. doi: 10.3389/fmicb.2022.798853

\author{
Bárbara M. Schultz ${ }^{1}$, Orlando A. Acevedo ${ }^{1}$, Alexis M. Kalergis ${ }^{1,2}$ and Susan M. Bueno ${ }^{1 *}$
}

${ }^{1}$ Millennium Institute on Immunology and Immunotherapy, Facultad de Ciencias Biológicas, Pontificia Universidad Católica de Chile, Santiago, Chile, ${ }^{2}$ Departamento de Endocrinología, Facultad de Medicina, Pontificia Universidad Católica de Chile, Santiago, Chile

Neutrophils are innate immune cells that play an essential role during the clearance of pathogens that can release chromatin structures coated by several cytoplasmatic and granular antibacterial proteins, called neutrophil extracellular traps (NETs). These supramolecular structures are produced to kill or immobilize several types of microorganisms, including bacteria and viruses. The contribution of the NET release process (or NETosis) to acute inflammation or the prevention of pathogen spreading depends on the specific microorganism involved in triggering this response. Furthermore, studies highlight the role of innate cells different from neutrophils in triggering the release of extracellular traps during bacterial infection. This review summarizes the contribution of NETs during bacterial and viral infections, explaining the molecular mechanisms involved in their formation and the relationship with different components of such pathogens.

Keywords: neutrophil extracellular traps (NETs), virulence factor, bacterial infection, viral infection, extracellular traps (ETs)

\section{INTRODUCTION}

Neutrophils, a type of polymorphonuclear cell, are one of the most abundant immune cells in the blood of humans, which increase upon infection with various microbial agents. Neutrophil precursors derived from the bone marrow enter the circulation and are recruited to the infected tissue, where they become fully activated. Activated neutrophils display multi-lobulated nuclei and produce many antimicrobial proteins, different types of granules and reactive chemical species. In addition, these cells present a wide variety of receptors as Pattern recognition receptors (PRRs) that recognize an array of pathogen-associated molecular patterns (PAMPs) and danger-associated molecular patterns (DAMPs). These interactions would enable the recognition of extracellular or intracellular pathogens to trigger responses to clear them (Segal, 2005; Thomas and Schroder, 2013). Furthermore, neutrophils have different mechanisms to develop an efficient bacterial killing, such as phagocytosis, NADPH oxidase-derived reactive oxygen species (ROS), degranulation of cytotoxic components, and antimicrobial peptides (Segal, 2005; Teng et al., 2017). Neutrophils can also release neutrophil extracellular traps (NETs) during microbial infection, a standard mechanism to prevent pathogen spreading during infectious diseases. This review summarizes the current knowledge relative to the mechanism of NET formation during bacterial and viral infections. 
Furthermore, we also discuss the role of extracellular traps released by other cells, different from neutrophils, which are produced during bacterial infections.

\section{NEUTROPHILS EXTRACELLULAR TRAPS AND NETosis}

Initial observations described that activated neutrophils were able to generate prominent extracellular structures composed of nuclear chromatin, histones, granular proteins such as neutrophil elastase (NE), myeloperoxidase (MPO), or cathepsin-G, and cytoplasmic proteins such as glycolytic enzymes and catalase, among others (Brinkmann et al., 2004; Urban et al., 2009). Further studies supported the role of NETs as elements able to capture, entrap and kill pathogenic microorganisms (Brinkmann et al., 2004; Papayannopoulos and Zychlinsky, 2009; Pilsczek et al., 2010; Kenny et al., 2017). Roughly, the NETs process begins with the recognition of the microorganism, which activates the NET pathway and allows the disruption of the nuclear and granular membrane, as well as the release of decondensed nuclear DNA into the cytoplasm. This decondensed chromatin mixes with nuclear, granular, and cytoplasmic content and the process ends with the disruption of the plasma membrane and the release of the lattice structure (Fuchs et al., 2007). The cell death process generated by the release of NETs has been denominated NETosis, which is different from other cell death processes described so far. For instance, it is different from apoptosis because it is caspase-independent and no DNA fragmentation is observed, which are hallmarks of the apoptotic process (Fuchs et al., 2007). It is also different from necrosis, because NETosis results in the fragmentation of the nuclear envelopment, which allows the formation of multiple vesicles that mix with the cytoplasm content, a process that does not happen during necrosis (Fuchs et al., 2007). Therefore, NETosis seems to be an innate immune mechanism used to control pathogen spreading by entrapping microorganisms and placing them in direct contact with a high amount of cell-derived antimicrobial molecules (Papayannopoulos and Zychlinsky, 2009). Initially, the release of NETs was thought to be related to the size of the pathogen, because one study shown that small microorganisms, such as single bacteria and unicellular yeast, do not induce NETosis and that the phagocytosis of these unicellular microbes inhibits the release of NETs by sequestering NE (Branzk et al., 2014). However, now it is known that NETs release takes place against fungus (Urban et al., 2005), protozoan (Guimarães-Costa et al., 2009), viruses (Souza et al., 2018), and bacteria (Brinkmann et al., 2004; de Jong et al., 2014). Furthermore, NETs release could be triggered by extracellular or intracellular pathogens (Chen et al., 2018) and, in some cases, the pathogen can generate a vital NETs release, in which the cell continues engulfing the microorganism (Yipp et al., 2012).

Although the function of NETs during microbial infection has a relevant role in pathogen control, it has been described that the overproduction of NETs is also related to tissue damage in several diseases, as such arthritis (Khandpur et al., 2013; Sur Chowdhury et al., 2014), allergies (Bouabe et al., 2011; Hu et al., 2016;
Toussaint et al., 2017), systemic lupus erythematosus (SLE) (Kessenbrock et al., 2009; Knight et al., 2012; Wang et al., 2015), and cancer (Cools-Lartigue et al., 2014; Razak et al., 2017; Wang et al., 2021). In the case of inflammatory diseases, it is possible that deficiencies in the mechanisms that prevent excessive tissue damage caused by NETs release are involved in their onset and progression. One of these regulatory mechanisms has been described in M1 macrophages, which degrade DNA in a caspase-activated dependent manner within $24 \mathrm{~h}$ postactivation (Nakazawa et al., 2016). Also, it has been described that monocytes-derived macrophages engulf the NETs, a process facilitated by DNase I and opsonization by C1q, without the secretion of pro-inflammatory cytokines after the ingestion (Farrera and Fadeel, 2013).

\section{Neutrophil Extracellular Trap Induction and Signaling}

Neutrophil extracellular traps release was described initially in response to lipopolysaccharide (LPS), interleukin-8 (IL-8), and phorbol myristate acetate (PMA) (Brinkmann et al., 2004; Hakkim et al., 2011). However, further studies have shown that diverse stimuli trigger NETs, such as platelet expressing TLR4 (Clark et al., 2007; Brown and McIntyre, 2011), PAMPs recognition by toll-like receptors (TLR), such as TLR2 (Cacciotto et al., 2016), TLR4 (Funchal et al., 2015), TLR7 (Hiroki et al., 2019), and TLR8 (Lood et al., 2017); calcium ionophores (Pilsczek et al., 2010; Douda et al., 2015), uric acid (Arai et al., 2014), high levels of glucose (Wong et al., 2015; Stoikou et al., 2017; Wang et al., 2018), autoantibodies (Kessenbrock et al., 2009), and interferon (IFN) (Martinelli et al., 2004).

The classical (or suicidal) NETs release, which is activated primarily by PMA, occurs after 3-4 h of stimulation, with the accompanying death of the cell (lytic NETosis). In physiological conditions, the process begins with the recognition of PAMPs or DAMPs by TLR, by receptors of complement system, by Fc-receptors (Fc $\gamma$ RIIa and Fc $\gamma$ RIIIb) (Chen et al., 2012) or by cytokines (Brinkmann et al., 2004; Garcia-Romo et al., 2011). Then, the Protein Kinase C (PKC) is activated, allowing the activation of the Raf-MEK-ERK pathway and the phosphorylation of a subunit of the NADPH oxidase 2 (NOX2) (Hakkim et al., 2011). Reactive oxygen species (ROS) produced by NOX2 act on the azurophilic granules to release the NE to the cytosol, in a process that requires the function of MPO (Metzler et al., 2014). ROS are also involved in the translocation of NE to the nucleus, promoting the decondensation of chromatin (Papayannopoulos et al., 2010; Metzler et al., 2014). This effect occurs in conjunction with the action of the Peptidyl arginine deiminase 4 (PAD4), an enzyme that citrullinate the histone $\mathrm{H} 3$ (Li et al., 2010) and allows NETs release in a process known as NOX2-dependent NETosis (Li et al., 2010). Further, the activity of PAD4 on NETs release is essential for an efficient DNA decondensation, the rupture of the NE granule, the nuclear DNA release into the cytoplasm, and the extracellular NETs release (Thiam et al., 2020).

There is also a NOX2-independent type of NETs release, also known as vital NETosis. This process could be triggered 
by recognition of LPS by PRRs as TLRs (Pilsczek et al., 2010; Yipp et al., 2012). As soon as $10 \mathrm{~min}$ after activation, the extrusion of vesicles loaded with nuclear DNA occurs, without breaking the plasma membrane, with minimal cell lysis and no ROS production (Pilsczek et al., 2010; Chen et al., 2012). The anuclear granulocytes generated -either cytoplasts or motile cytokineplasts- due to vital NETosis retain antimicrobial mechanisms as phagocytosis, transmigration, and chemotaxis (Malawista et al., 1989, 2006). Furthermore, the anuclear neutrophils derived from this process, which are close to $10 \%$ of total neutrophils undergoing NETosis, contain intracellular bacteria due to intact plasma membrane and maintain an active phagolysosome, implying that NETs release and phagocytosis can work simultaneously and independently (Yipp et al., 2012). The importance of vital NETs release is that the cell still contributes to the antibacterial mechanisms (Pilsczek et al., 2010; Yipp et al., 2012). However, it is still unknown how long last and how functional these anuclear cells are. Another type of NETs release that retains the survival of the cell is described in neutrophils primed with GM-CSF and stimulated with LPS or with complement components such as $\mathrm{C} 5 \mathrm{a}$, which induce mitochondrial DNA release, a rapid process that depend on ROS (Yousefi et al., 2009; McIlroy et al., 2014). This type of NETs release by viable neutrophils requires glycolytic ATP production for rearrangements of the microtubule network and F-actin (Amini et al., 2018).

Also, NETs release is induced by calcium ionophore or ionomycin, which induce a faster NETs release than the classical NOX2-dependent NETs release and independent of ERK activation (Douda et al., 2015). However, this pathway requires the calcium-activated potassium channel of small conductance 3 (SK channel), which activates mitochondrial ROS production (Douda et al., 2015). In consequence, this process induces the opening of the non-selective mitochondrial permeability transition pore, which results in the accumulation of mitochondrial ROS that causes the activation of NOX2 (Vorobjeva, 2020). Using human neutrophils from healthy controls or from patients with the chronic granulomatous disease (CGD), which lacks NADPH Oxidase, it was demonstrated that NET release can indeed be induced by mitochondrial ROS production (Vorobjeva, 2020).

The last NETs release induction pathway identified so far is mediated by cytosolic LPS derived from intracellular Gram-negative pathogens, such as Salmonella enterica serovar Typhimurium (Chen et al., 2018). This stimulus activates the non-canonical inflammasome, which is a caspase-11-dependent pathway, and triggers the neutrophil gasdermin-D (GSDMD)-dependent death (Chen et al., 2018). In this case, the action of ROS or PAD4 is not required, because GSDM-D can directly generate pores in the nuclear and plasma membranes (Chen et al., 2018).

It is essential to mention that not all stimuli activate the specific proteins discussed above. Although five different stimuli induce NETs production, killed bacteria and degraded proteins activate different pathways as compared to NOX2-dependent NETosis (Kenny et al., 2017). For instance, Candida albicans and group B of Streptococcus (GBS) induce NETs independently of histone citrullination mediated by PAD4 (Kenny et al., 2017; Guiducci et al., 2018). In another study, Leishmania amazonensis induced both types of NETs release: the classical NOX2-dependent NETosis (which is dependent on the action of PAD4, but independent of MPO) and the early/rapid NETosis (which is ROS and NE-independent, but dependent on the activity of PAD4) (Rochael et al., 2015). All these studies suggest that the NETosis process is not activated just by one or two pathways but depends on the nature of the stimulus and can be very diverse in terms of activation.

It has been described that other factors produced due to the host immune response activation can also induce NETs during a bacterial infection. As an example, it has been described that platelets can recognize Gram-negative and -positive bacteria and other stimuli through TLR-4, inducing the adhesion to neutrophil and NETs release (Clark et al., 2007). Accordingly, elimination of platelets or the inhibition of TLR4 expressed by platelets substantially reduces NETs release (Clark et al., 2007). The importance of platelets is observed when the bacteria induce virulence factors that promote apoptosis of these cells, causing thrombocytopenia and generating a more severe infection that affects the immune response of the neutrophils (Kraemer et al., 2012). Other factors produced during immune response activation that cause NETs release in a ROS- dependent manner are of pro-inflammatory cytokines such as TNF $\alpha$, IL-1 $\beta$, or IL8 (Keshari et al., 2012) and macrophage Migration Inhibitory Factor (MIF) secreted by red blood cells during Plasmodium infection, which induce NETosis in a C-X-C chemokine receptor type 4 (CXCR4) dependent manner (Rodrigues et al., 2020).

\section{OTHER IMMUNE CELLS THAT PRODUCE EXTRACELLULAR TRAPS}

Although NETs are the most studied Extracellular Traps (ET), other immune cells are also able to produce this kind of structures, such as eosinophils (Ueki et al., 2013), basophils (Yousefi et al., 2015), macrophages (Aulik et al., 2012), and mast cells (Naqvi et al., 2017).

\section{Eosinophils Extracellular Traps}

Eosinophils extracellular traps (EETs) are released similarly to NETs. They are triggered due to activation by bacteria (Yousefi et al., 2008; Gevaert et al., 2017), fungi (Muniz et al., 2018; Omokawa et al., 2018), and by PMA and calcium ionophore stimulation (Ueki et al., 2013, 2016). In addition, it has been described that EETs contain entire eosinophil granules and granule-derived proteins (Mukherjee et al., 2018). Furthermore, mitochondrial DNA-derived EETs has also been reported in response to LPS stimulation on previously primed cells in in vitro experiments, which did not involve cell death (Yousefi et al., 2008). However, other studies have shown that EETs can also be produced by nuclear DNA, and ROS production dependent on NOX activation, in a similar pathway to the lytic NETosis (Ueki et al., 2013). The presence of EETs has been reported during allergies (Dworski et al., 2011), respiratory tract disease (Cunha et al., 2014; Ueki et al., 2016; 
Echevarría et al., 2017), and skin disease (Simon et al., 2011; Morshed et al., 2012).

\section{Basophils Extracellular Traps}

The release of basophils extracellular traps (BETs) has not been deeply studied. However, it has been observed in activated cells in response to Gram-positive (Morshed et al., 2014) and -negative bacteria (Yousefi et al., 2015). It has been described that ETs derived from mice or human basophils have the capacity to entrap Escherichia coli and Staphylococcus aureus (Yousefi et al., 2015), equivalent to NETs (Brinkmann et al., 2004). Another in vitro study performed in basophils derived from mice and humans reported that BETs are released in a mitochondrial ROSdependent manner, without activation of NOX, and are also composed of mitochondrial DNA (Yousefi et al., 2015). This process can take place as rapidly as $5 \mathrm{~min}$ post-stimulation (Yousefi et al., 2008) with the concomitant cell survival of human and mouse primed basophils (Morshed et al., 2014). Lastly, BETs release was reported in vivo studies during $N$. brasiliensis infection in mice and inflammatory skin diseases in the human epidermis (Morshed et al., 2014).

\section{Macrophages and Monocytes Extracellular Traps}

Macrophages and monocyte extracellular traps (METs) have been studied in different types of cells, such as RAW264.7, human alveolar macrophage, murine peritoneal macrophages, and bovine monocytes (Chow et al., 2010; Doster et al., 2018). Experiments performed in in vitro and in vivo models have described that TNF- $\alpha$ is an inducer of ETs in RAW264.7 macrophages. The concomitant presence of citrullinated histones suggests that ETosis in macrophages is mediated by PAD-2 (Mohanan et al., 2013). Various distinct stimuli can induce METs, including Gram-negative (Webster et al., 2010; Liu et al., 2014) and -positive bacteria (Chow et al., 2010; Hellenbrand et al., 2013; Shen et al., 2016), parasites (Muñoz-Caro et al., 2014; Reichel et al., 2015), fungi (Liu et al., 2014; Halder et al., 2017; Loureiro et al., 2019), PMA (Chow et al., 2010), and TNF- $\alpha$ (Mohanan et al., 2013), leading to cell death. Monocytederived macrophages from human peripheral blood have also been described to release METs after the stimulation with IFN$\gamma$ during infection with Mycobacterium tuberculosis (Wong and Jacobs, 2013). Escherichia coli also induces the release of METs, composed of nuclear and mitochondrial DNA, histones, MPO, and lysozyme (Liu et al., 2014), independently of ROS production by NOX (Liu et al., 2014). Like NETs, METs can be produced by different molecular pathways, dependent or independent of ROS and caspase-1, in human monocytes derived from peripheral blood when infected with Escherichia coli and Klebsiella pneumoniae infection (Webster et al., 2010). METs have been also observed in bone marrow-derived macrophage and J774A.1 macrophages infected with a mutant strain of Salmonella enterica serovar Typhimurium, showing that METs can kill and entrap at least $10 \%$ of the initial inoculum (Mónaco et al., 2021). However, more studies are necessary to determine the different pathways that induce METs release and to identify similarities between NETs and METs, because the ETs from macrophages depends on the specie, the state of differentiation, microenvironment, and state polarization (Doster et al., 2018).

\section{Mast Cells Extracellular Traps}

The release of mast cells extracellular traps (MCETs) was first described in response to PMA, with ROS production by NOX (Von Köckritz-Blickwede et al., 2008; Campillo-Navarro et al., 2018). MCETs are composed of nuclear DNA, histones, and granular proteins, such as tryptase and cathelicidin AMP LL37 (Campillo-Navarro et al., 2017), which suggest that MCETs and NETs are produced in a similar manner (Von KöckritzBlickwede et al., 2008). It has been shown that although mast cells cannot phagocytose Streptococcus pyogenes, the release of MCETs allows the growth inhibition of the bacteria (Von KöckritzBlickwede et al., 2008). Furthermore, heat-killed Mycobacterium tuberculosis can induce the release of MCETs after $2 \mathrm{~h}$ of stimulation; however, the live pathogen can modulate the release of these ETs (Campillo-Navarro et al., 2018). MCETs are released in a ROS-dependent manner in the case of Listeria monocytogenes (Campillo-Navarro et al., 2017).

\section{ROLE OF NEUTROPHIL EXTRACELLULAR TRAP DURING BACTERIAL INFECTION}

The contribution of NETs during bacterial infection is not completely clear. It was initially thought that it promoted the clearance of bacteria by facilitating the entrapping and killing of these pathogens (Riyapa et al., 2012). However, NETs release has a bacteriostatic rather than a bactericidal effect because it mainly affects the growth of the bacteria and eventually could aid the killing (Menegazzi et al., 2012). Nevertheless, the DNA exerts antimicrobial properties by cation chelation and the disruption of the cell membrane (Halverson et al., 2015). Furthermore, experiments in primary human neutrophils showed that NETs could entrap bacteria, including Pseudomonas aeruginosa ( $P$. aeruginosa) and Staphylococcus aureus (S. aureus), without killing them but affecting the ability of the complement to kill them (Azzouz et al., 2018). Also, the condition in which the NETs are produced affects the antimicrobial properties, observing that NETs in static conditions present fewer killing abilities than the NETs released in dynamic conditions (Azzouz et al., 2018).

On the other hand, NETs release could result in collateral effects due to the production of antimicrobial components that can lead to exacerbated inflammation, causing tissue damage (Xu et al., 2009). However, it has been described that the granular proteins with bactericidal activities released within the NET act mainly as a regulator of inflammation due to the action on different cytokines, rather than as a bactericidal mechanisms (Clancy, 2018).

Notably, while almost all bacteria can induce ETs, several microorganisms have evolved molecular strategies to inhibit this host mechanism of defense to promote microbial proliferation and dissemination (Malachowa et al., 2013; Seper et al., 2013; Storisteanu et al., 2017). Evasion strategies can be due to the 
inhibition of NET release by down-regulating host inflammatory responses, the degradation of NETs using pathogen-derived DNases, and/or by the resistance to the microbicidal components of NETs (Halverson et al., 2015; Storisteanu et al., 2017; Figure 1). In this section, we will review some examples of virulence factors that induce the NETs, which can favor or not the clearance, and some evasion strategies used to avoid the antimicrobial mechanisms and, in some cases, take advantage of this immune response. These evasion mechanisms have been summarized in Table 1.

\section{Pseudomonas aeruginosa}

Pseudomonas aeruginosa is an encapsulated, Gram-negative bacterium associated with severe illnesses in healthy and individuals with comorbidities and an important cause of nosocomial infection in cystic fibrosis patients (Davies, 2002). Pyocyanin, a redox-active pigment secreted to the airways by the biofilm, is associated with an increase in oxidative stress and the inflammation generated during the disease (Rada et al., 2013). Also, this virulence factors increases the induction of NETs by the NOX2-dependent pathway (Rada et al., 2013). However, NETs extrusion does not have any effect in entrapping or killing the bacteria but in decreasing the functionality of the lungs and increasing the inflammatory conditions found in patients with cystic fibrosis (Rada et al., 2013).

The sputum of cystic fibrosis patients presents a large amount of DNA because neutrophils is one of the main types of immune cells recruited to the airways and the NETs release by these cells allow the characteristic sputum's mucus structure (Manzenreiter, 2012). In this sense, it has been observed that the concentration of extracellular DNA in the sputum generate the lysis of the bacteria (Halverson et al., 2015). However, P. aeruginosa contains virulence factors that allow the degradation of the NETs structure, which involves an operon encoding two DNA-modifying type

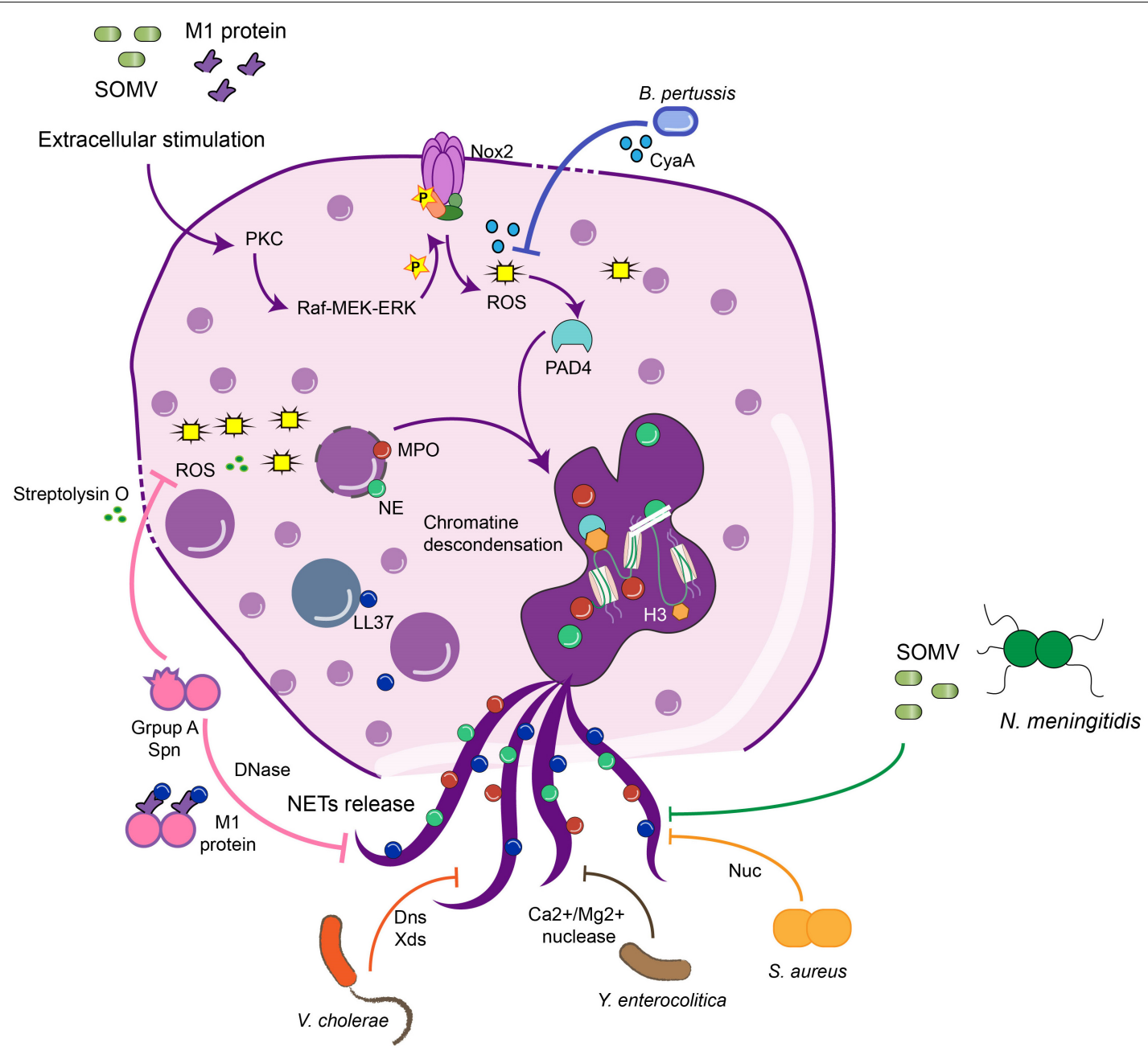

FIGURE 1 | Bacteria virulence factors that avoid NETs release against bacterial infection. Bacteria have evolved to develop different virulence factors to avoid the function of NETs, inhibiting different steps in the pathways required for the NETs release. B. Pertussis or GAS inhibit the action of ROS production by streptolysin O during the NETs pathway, which in the end inhibits the release of the structure. Nucleases are the main virulence factor shared among the bacteria which dismantle the NETs structure, and in this sense, the bacteria can disseminate and generate the disease. GAS, Group A Streptococcus; MPO, myeloperoxidase; NE, neutrophil elastase; SOMV, small vesicles from the outer membrane into the environment; PAD4, peptidylarginine deiminase 4; Nuc, nuclease; LL37, cathelicidin. 
TABLE 1 | Virulence factors that interfere with NET function during bacterial infection.

\begin{tabular}{|c|c|c|c|}
\hline & NET inhibition & Type of inhibition of NET function & References \\
\hline \multirow[t]{3}{*}{ Pseudomonas aeruginosa } & Dnase (eddB), phosphatase (eddA) & 2 & Rada et al., 2013; Wilton et al., 2018 \\
\hline & Biofilm formation & 3 & Thanabalasuriar et al., 2019 \\
\hline & Pyocyanin & 1 & Rada et al., 2013 \\
\hline \multirow[t]{2}{*}{ Mycobacterium tuberculosis } & Probably the level of lipids of it envelops & 3 & Liu et al., 2019; Sun et al., 2020 \\
\hline & ESAT- 6 protein by the ESX-1 type & 1 & Francis et al., 2014 \\
\hline \multirow[t]{3}{*}{$\begin{array}{l}\text { Staphylococcus } \\
\text { aureus }\end{array}$} & Biofilm formation & 3 & $\begin{array}{l}\text { Malachowa et al., 2013; Bhattacharya et al., } \\
2018\end{array}$ \\
\hline & $\begin{array}{l}\text { Eap, DNA binding protein, Nuc, } \\
\text { adenosin synthase }\end{array}$ & 2 & $\begin{array}{l}\text { Chavakis et al., 2005; Thammavongsa et al., } \\
\text { 2013; Eisenbeis et al., } 2018\end{array}$ \\
\hline & Leukotoxin GH & 1 & Malachowa et al., 2013 \\
\hline Bordetella spp. & ACT and CyaA & 1 & Eby et al., 2014; Gorgojo et al., 2017 \\
\hline \multirow[t]{7}{*}{ Streptococcus spp. } & Sda1 & 3 & $\begin{array}{l}\text { Lauth et al., 2009; Buchanan et al., 2006; } \\
\text { Moon et al., } 2016\end{array}$ \\
\hline & SpnA & 3 & Chang et al., 2011 \\
\hline & endA & 3 & Beiter et al., 2006; Zhu et al., 2013 \\
\hline & Capsule & 3 & Wartha et al., 2007 \\
\hline & dlt operon & 3 & Wartha et al., 2007 \\
\hline & Streptolysin O & 1 & Uchiyama et al., 2015 \\
\hline & M1 toxin & 1 & Lauth et al., 2009 \\
\hline $\begin{array}{l}\text { Yersinia } \\
\text { enterocolitica }\end{array}$ & Nuclease & 2 & Möllerherm et al., 2015 \\
\hline Vibrio cholerae & Dns and $X d s$ & 2 & Seper et al., 2013 \\
\hline Mycoplasma pneumoniae & Mpn491 & 2 & Yamamoto et al., 2017 \\
\hline \multirow{4}{*}{$\begin{array}{l}\text { Neisseria } \\
\text { meningitidis }\end{array}$} & Nuc & 2 & Lappann et al., 2013 \\
\hline & Phosphoethanolamine transferase & 3 & Lappann et al., 2013 \\
\hline & ZnuD & 2 & Lappann et al., 2013 \\
\hline & SOMVs & 3 & Lappann et al., 2013 \\
\hline Burkholderia pseudomallei & TTSS and capsule polysaccharide I & 1 & Riyapa et al., 2012 \\
\hline
\end{tabular}

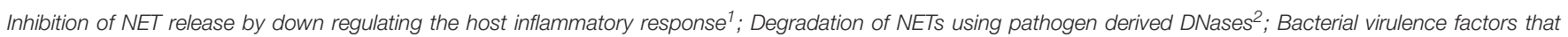
evade $N E T S^{3}$.

II secreted enzymes: a DNase $(e d d B)$ and a phosphatase (eddA) (Wilton et al., 2018). These two enzymes work together at degrading the extracellular DNA: the phosphatase acts on the phosphodiester backbone of the DNA, removing the phosphates and altering the function, but no the structure of the DNA (neutralizes its cation-chelating, antimicrobial activity), while the DNase disassembles the NETs and promotes bacterial survival (Wilton et al., 2018). This allows the bacteria to tolerate the ETs produced by the neutrophils, in addition to the formation of the biofilms that avoid the NETs antimicrobial function. This role of the NETs in the consistency of the sputum has led to the evaluation of rhDNases used as treatment (Guichard et al., 2018).

In cystic fibrosis patients, $P$. aeruginosa can produce keratitis caused by a biofilm formed in the outer eye surface (Saraswathi and Beuerman, 2015; Naimie et al., 2016). In a mice model of keratitis caused by $P$. aeruginosa, it was observed that the Type Three Secretion System (TTSS) and the bacterial Psl exopolysaccharide contribute to biofilm formation (Jabalameli et al., 2012; Naimie et al., 2016) and the release of NETs (Thanabalasuriar et al., 2019). In this model, NETs production allows the maturation of the biofilm formation and the inhibition of the dissemination to the brain. However, NETs formation generates a severe local ulcer in the eye without killing the pathogen (Thanabalasuriar et al., 2019).

\section{Mycobacterium tuberculosis}

Mycobacterium tuberculosis (Mtb) is the causative agent of tuberculosis, a chronic infectious lung disease that affects over one-third of the global population and causes 8 million new cases per year (Theodor, 2013; Ramazanzadeh et al., 2015). Mtb secrete the protein ESAT-6 by the ESX-1 type VII secretion system, increasing $\mathrm{Ca}^{2+}$ influx inside the cell, activating calpain, a cysteine protease, which finally allows the release of NETs structures through a pathway similar to the activation produced by ionomycin (Francis et al., 2014). This mechanism contributes to lung pathology and generates an environment more permissive to infection (Francis et al., 2014). Furthermore, in neutrophils obtained from human alveolar lining fluid, ETs structures fail to kill Mtb but contribute to reducing the bacterial dissemination (Arcos et al., 2015).

It is also known that the bacteria Mycobacterium bovis or Bacillus Calmette Guerin (BCG), which is currently used as a vaccine against Mycobacterium tuberculosis, can trigger NET formation (Liu et al., 2019; Sun et al., 2020). This bacterium is 
currently used to induce protection against heterologous antigens as well (Claudia et al., 2015; Céspedes et al., 2017; Goulart et al., 2017; Soto et al., 2018; Covián et al., 2019) and is also used as a immunotherapy in different diseases in humans. The NETs pathway activated by BCG depends mainly on ROS production (Liu et al., 2019; Sun et al., 2020). Furthermore, it was also shown that NETs entrap but do not kill bacteria, which may be due to the high lipid levels of the mycobacterial envelope that impair NET-mediated killing (Liu et al., 2019; Sun et al., 2020).

\section{Staphylococcus aureus}

Staphylococcus aureus is a Gram-positive bacterium usually part of the normal microbiota (Krismer et al., 2017). However, this bacterium can act as an opportunistic pathogen and eventually be the causative agent of significant systemic disease due to the activity of several virulence factors. It was observed in human neutrophils that $S$. aureus induces NETs due to a leukotoxin GH (LukGH), which generates NETs release and entrap but does not kill the bacteria (Malachowa et al., 2013). In a porcine chronic burn model, S. aureus biofilms -in opposite to singlecell populations- promote the formation of NETs through the combined action of leukocidins Panton-Valentine leukocidin (PVL) and $\gamma$-hemolysin AB (Bhattacharya et al., 2018) without the avoidance of bacterial dissemination (Malachowa et al., 2013). Through this response, S. aureus persisted because the antimicrobial activity of NETs was ineffective at eliminating the bacteria associated with the biofilm (Bhattacharya et al., 2018; Speziale and Pietrocola, 2021).

Staphylococcus aureus also produce different enzymes to interfere with the antimicrobial property of the extracellular DNA, such as a DNA binding protein, the extracellular adherence protein (Eap) (Chavakis et al., 2005), and a nuclease (Nuc). These enzymes allow the escape from the NETs structure, delay the bacteria clearance and increase the mortality caused by the infection. Also, this nuclease is related to the persistence of the bacteria in cystic fibrosis patients (Berends et al., 2010; Herzog et al., 2019). Eap binds to linearized extracellular DNA, aggregates this structure, and interferes with the antimicrobial and trapping function of NETs structure in human-derived neutrophils (Chavakis et al., 2005; Eisenbeis et al., 2018). On the other side, the adenosine synthase (Thammavongsa et al., 2013) in conjunction with a nuclease Nuc are required to generate deoxyadenosine (dAdo) from dsDNA derived from the NETs release in human-derived neutrophils, inducing caspase-3mediated death on macrophages that are recruited to the site of infection (Figure 1; Thammavongsa et al., 2013).

\section{Bordetella spp.}

Bordetella pertussis (B. pertussis) is a Gram-negative bacterium and the causative agent of whooping cough, causing approximately 151,000 cases globally in 2018, according to the World Health Organization (WHO). This bacterium expresses several virulence factors as pertussis and adenylate cyclase toxins (Ladant and Ullmann, 1999; Mooi et al., 2009). The adenylate cyclase toxin (ACT) prolongs the life span of human-derived neutrophils and inhibits the release of NETs by increasing cAMP levels and inhibiting intracellular ROS production (Eby et al., 2014). Bordetella parapertussis also generates whooping cough (Watanabe and Nagai, 2004; Bouchez and Guiso, 2015) and produce an adenylate cyclase enzyme, CyaA, that is released to the extracellular medium and inhibits the ROS production generated by NOX (Gorgojo et al., 2017), inhibiting the NET induction in human-derived neutrophils (Figure 1). However, NETs induced by these bacteria can trap and kill bacteria because they fail to express other virulence factors to dismantle the structure (Gorgojo et al., 2017).

\section{Streptococcus spp.}

Group A Streptococcus (GAS) is a group of Gram-positive, $\beta$-hemolytic bacteria, part of the normal microbiota that can generate between 10,649 to13,434 cases of invasive GAS infections that occur in the United States annually (Stevens, 1992; Deutscher et al., 2011; Nelson et al., 2016). In human neutrophils, GAS expresses the M1 exotoxin, a virulence factor, which induces ETs in neutrophils and mast cells by associating with fibrinogen and forming a complex that stimulates neutrophils (Lauth et al., 2009). However, these ETs do not kill the pathogen because the M1 exotoxin allows the pathogen's survival in the presence of cathelicidin and antimicrobial peptides (Lauth et al., 2009). Besides this, GAS expresses a DNase Sda1, which promotes the degradation of the NETs (Buchanan et al., 2006; Moon et al., 2016). Streptococcus pyogenes is the main species that belongs to GAS. Besides Sda1 (Buchanan et al., 2006), it produces another nuclease, SpnA, that is not secreted but is anchored to the cell wall and allows bacteria survival in human blood and resist NETs killing (Chang et al., 2011). Also streptolysin O, a pore-forming toxin, induces eukaryotic cell lysis (Uchiyama et al., 2015) due to a decrease in the oxidative burst and, consequently, inhibits the release of NETs and the extracellular killing (Uchiyama et al., 2015) allowing bacteria survival in the bloodstream.

Streptococcus pneumoniae (S. pneumoniae) is an alphahemolytic bacterium and the leading cause of pneumonia worldwide, mainly in children, that caused 294,000 deaths during 2015 (Wahl et al., 2018). It has been described that the induction of NETs in this disease has been correlated with an adverse outcome in community-acquired pneumonia (CAP) (Gray, 2018). However, in a mice model of infection, it was observed that although NETs can entrap S. pneumoniae (Figure 1), it fails to kill this pathogen due to the expression of endA, a bacterial cell-bound DNase. EndA destroys the NETs and promotes the spreading of bacteria from the upper airways to the lungs and bloodstream, promoting a more invasive disease (Beiter et al., 2006; Zhu et al., 2013). The S. pneumoniae capsule also contributes to avoiding the bacterial entrapping by NETs (Wartha et al., 2007). Due to the operon $d l t$ that produces the modification of lipoteichoic acids, which introduce positive charge into alanine amino acid residues, which then caused electrochemical repulsion of antimicrobial proteins present in NETs (Wartha et al., 2007). This molecular mechanism contributes to bacterial resistance to the killing by NETs (Wartha et al., 2007). Importantly, it has been described that IL-10 production by neutrophils in C57BL/6 mice can modulate the lung injury induced by $S$. pneumoniae infection (González et al., 2021). It has been described that IL-10 can inhibit the TLR7/8 
activation pathway, which prevents the generation of ROS and the translocation of NE to the nucleus, decreasing the NETs release (Saitoh et al., 2012), but it is unknown whether IL-10 producing neutrophils are still able to produce NETs.

\section{Klebsiella pneumoniae}

Klebsiella pneumoniae ( $K$. pneumoniae) is a Gram-negative bacteria found in the nasopharynx and the intestinal tract. It is the most relevant species for humans of the genus Klebsiella spp. and a significant cause of nosocomial infection, responsible for severe diseases such as septicemia, pneumonia and urinary tract infections (Podschun and Ullmann, 1998). In the United States, the infection caused by Carbapenem-resistant Enterobacteriaceae (CRE) produce up to 2.93 cases per 100,000 people (Guh et al., 2015). CRE sequence type 258 (CRKP-ST258) is a multidrugresistant strain that has spread worldwide, which evades the neutrophil immune response, preventing intracellular killing and NETs release in neutrophils derived from human (Castillo et al., 2019) and mice (Peñaloza et al., 2020). In human neutrophils, it was described that inhibition of NETs release was due to the avoidance of ROS production, produced to in part to the polysaccharide of the LPS (Castillo et al., 2019). In mouse neutrophils, no differences in ROS or MPO was observed when compared to a non-pathogenic K. pneumoniae, but differences in the acidification of the phagolysosome was described, which affects the functionality of MPO (Peñaloza et al., 2020). Another in vitro study performed in humanderived neutrophils showed that $K$. pneumoniae carbapenemresistant affects the release of NETs due to the mobilization of primary granules due to a non-soluble virulence factor (Birnberg-Weiss et al., 2021).

\section{Other Gram-Negative Bacteria}

Yersinia enterocolitica is the causative agent of yersiniosis autolimited gastroenteritis (Marks et al., 2018), producing 9.7 cases each 100,000 people per year, being children between 6 and 11 months the most affected (Yagüe-Muñoz et al., 2019). Three different serotypes (O:3, O:8, and O:9) were tested for induction of NETs release in human-derived neutrophils and all of them induce and degrade NETs by the action of $\mathrm{Ca}^{2+} / \mathrm{Mg}^{2+}$-dependent NET-degrading nuclease (Figure 1; Möllerherm et al., 2015). Secretory diarrheal disease caused by Vibrio cholerae, the causative agent of a previously considered non-inflammatory disease, has recently been shown to recruit a high number of neutrophils (Queen and Satchell, 2012). Human-derived neutrophils in direct contact with Vibrio release NETs in an oxidative burst-dependent fashion and can kill the bacteria (Seper et al., 2013). Nevertheless, at the same time, bacteria induce two extracellular nucleases: Dns and Xds, which enhance pathogen dissemination (Figure 1; Seper et al., 2013). Mycoplasma pneumoniae causes atypical pneumonia and produces an extracellular nuclease, Mpn491, that requires $\mathrm{Mg}^{2+}$ to degrade the NETs structure in in vitro and in vivo models (Yamamoto et al., 2017).

Neisseria meningitidis (meningococci) is a Gram-negative bacterium that can cause severe septicemia in children and is a restricted human pathogen. Neisseria also presents a putatively secreted thermonuclease denominated Nuc, which induces and degrades NETs from human-derived blood, contributing to the escape and the avoidance of the killing of the pathogen (Lappann et al., 2013). Meningococcus display at least three different mechanisms to avoid NETs killing: (1) the lipid A modification of LPS with a phosphoethanolamine transferase is crucial for the survival of Neisseria meningitidis in the presence of NETs in vitro, due to this modification, bacteria are protected from the action of the cathepsin- $G$ antimicrobial peptide; (2) it produces an outer membrane receptor $\mathrm{ZnuD}$, which is crucial to uptake the $\mathrm{Zn}^{2+}$ and promote the nutritional resistance in the environment induced by the NETs; (3) it secrete small vesicles from the outer membrane into the environment (SOMVs), which have been identified as the inducers of NETs release and also bind to the NETs structure to reduce its bacteriostatic effect (Lappann et al., 2013; Figure 1).

Burkholderia pseudomallei is a Gram-negative bacterium and the causative agent of melioidosis, a zoonotic infection leading to lung, localized or systemic infection. It is a critical pathogen in diabetic patients, and it is estimated that exist 165,000 human melioidosis cases per year, of which 89,000 people die with a case fatality rate of more than 50\% (Chanchamroen et al., 2009; Limmathurotsakul et al., 2010; Birnie et al., 2019). This bacterium triggers the induction of NOX2-dependent NETs released in human- and mouse-derived neutrophils, and in addition to entrapping bacteria, NETs can significantly reduce the initial inoculum (Riyapa et al., 2012). However, the TTSS and capsular polysaccharide- 1 expressed by these bacteria can regulate the proportion of NETs released, possibly by regulating the oxidative burst (Riyapa et al., 2012).

Leptospira spp. is an important cause of zoonotic infection, which can generate rapid bloodstream dissemination and affect mainly the kidney function, and in this manner, the carrier disseminates the infection (Scharrig et al., 2015). It was shown that Leptospira interrogans serovar Copenhagen strain Fiocruz L1-130 (LIC) induces NETs released by human- and mousederived neutrophils, which entraps and kills bacteria, decreasing the CFU content. However, some pathogenic strains can degrade the dsDNA structure, implying that the NETs function depends on the infecting bacterial strain (Scharrig et al., 2015).

\section{CONTRIBUTION OF NEUTROPHIL EXTRACELLULAR TRAP TO VIRAL INFECTIONS}

In addition to the widely described role of bacteria in triggering NETs release, increasing evidence indicates that viruses can also promote NET formation (Jenne et al., 2013; Souza et al., 2018). Current data suggest that PRRs expressed on the surface or internal compartments of neutrophils, such as endosomes, play a crucial role in triggering NETs release (Saitoh et al., 2012). Other studies suggest that, as observed for bacteria, viruses may counteract the mechanisms involved in triggering NETs release during infection (Martinez et al., 1996). It is also documented that mechanisms underlying NET release induced by viruses may differ mechanistically depending on the specific pathogen 
involved (Muraro et al., 2018; Chan et al., 2020). Along these lines, it has been described that NET release may either promote or prevent the viral-induced pathology (Jenne et al., 2013; Al-Anazi et al., 2020).

In the case of Human Immunodeficiency Virus-1 (HIV-1), it has been documented that NETs promote pathogen clearance through the concerted action of MPO, $\alpha$-defensin, and histones (Saitoh et al., 2012). In this work, cultivated neutrophils were exposed to HIV and the results suggest that NETs release induced by infection occurs through the engagement of endosomeexpressed TLR7 and TLR8, which induce ROS-dependent NET formation (Figure 2). Therefore, in this case, NET formation benefits the infected host to prevent pathogen spreading (Saitoh et al., 2012). Remarkably, HIV-1 counteracts this response by inducing the production of IL-10 by DCs, which suppresses the ROS-dependent response that results in an impaired NETdependent HIV-1 elimination.
Another example of a protective role of NETs during viral infection is the case of the myxoma virus (MYXV) (Jenne et al., 2013). This oncolytic virus is characterized by its ability to infect rabbits and kill human and murine cancer cells (Lun et al., 2005). Therefore, it has been proposed as a viralbased therapy for cancer (Rahman and McFadden, 2020). In the mice model, intravenous infection with MYVX induces massive recruitment of neutrophils and platelets to the liver vasculature (Jenne et al., 2013). At this site, the interaction of both subsets of cells promotes the release of NETs that can protect host cells from MYVX infection, and this protective effect was reversed by DNase treatment (Jenne et al., 2013). These results highlight the role of extracellular DNA in preventing viral dissemination (Jenne et al., 2013). According to this notion, it has also been shown that viral proteins with DNase activity derived from Herpesviruses can also degrade NETs, thereby preventing the formation of NETs and promoting viral spreading (Martinez et al., 1996).

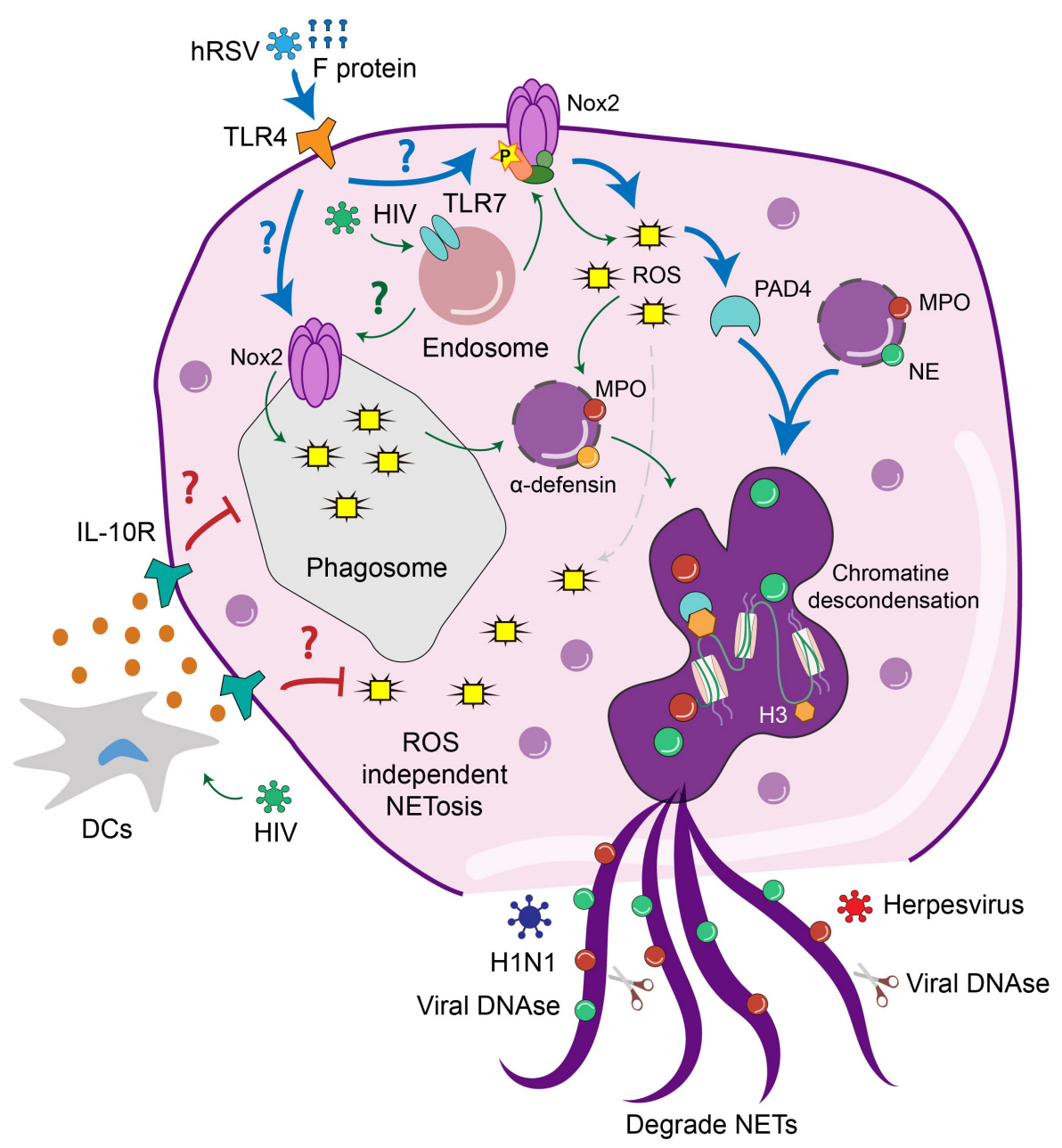

FIGURE 2 | The release and activity of NETs is modulated by viral infection. Interaction of neutrophils with different viruses activates extracellular or intracellular pathways that lead to the NET formation. HIV triggers TLR7 signaling in the endosomes of neutrophils leading to the production of ROS and subsequently NETs release. HIV infection of DCs triggers the production of IL-10, which suppresses the formation of NETs and may allow pathogen spreading. HRSV infection triggers TLR4 signaling at the cell surface, which results in ROS-dependent NETs release. In the case of H1N1, this virus triggers ROS independent NETs release which may prevent pathogen spreading. In contrast, the activity of DNases from Herpesviruses can degrade NETs to allow viral dissemination. 
Influenza is another respiratory virus that circulates worldwide and can trigger NETs release (Ashar et al., 2018; Zhu et al., 2018; Chan et al., 2020). Annual influenza cases lead to extensive mortality, especially in people older than 65 years. According to a recent study, it was estimated that influenza infection accounts for 4.0-8.8 deaths per 100,000 individuals annually (Iuliano et al., 2018). Sudden onset of fever, headache, sore throat, and a runny nose develops upon infection. Illnesses range from mild to severe and can lead to the death of infected individuals (Ryu and Cowling, 2020). Patients with severe influenza showed elevated plasma NET release, measured as the level of cell-free DNA and DNA-MPO complexes (Zhu et al., 2018). In addition, isolated neutrophils from these subjects released higher amounts of MPO-DNA complex in response to IL- 8 or LPS (Zhu et al., 2018). Interestingly NETs from H7N9 and H1N1 patients increased the permeability of alveolar epithelial cells, and, consequently, NET production was positively correlated with acute inflammation (Zhu et al., 2018). Together, this data indicates that high levels of NETs correlate with influenza severity. Thus, evaluation of NETs in plasma could be an excellent strategy to predict the prognosis of IAV patients (Zhu et al., 2018).

Histones present in the lungs of IAV infected mice have been shown to induce cytotoxicity on cultured human lung epithelial cells (Ashar et al., 2018). Furthermore, histones also bind to platelets within thrombi in infected mouse lungs (Ashar et al., 2018). Nasal aspirates from influenza-infected patients also have elevated levels of extracellular histones, which may serve as a clinical marker of pulmonary injury (Ashar et al., 2018). In vitro studies showed that histones inhibited influenza growth. However, in the mice model, in vivo treatment with histones did not yield antiviral effects and instead increased lung illness (Ashar et al., 2018). The blockade of histones with anti-histone antibodies caused a significant reduction of lung pathology in lethal influenza-challenged mice and enhanced protection when co-administered with the antiviral oseltamivir (Ashar et al., 2018). These data highlight the pathogenic effects of extracellular histones in pulmonary injury during influenza infection. These findings suggest that targeting histones represents a novel therapeutic strategy for treating influenza pneumonia (Ashar et al., 2018).

Another study described that NETs release is triggered only by some IAV specific strains (Chan et al., 2020). For example, it is indicated that the $\mathrm{H} 5 \mathrm{~N} 1$ strain fails to stimulate NETs release, whereas $\mathrm{H} 1 \mathrm{~N} 1$ infection stimulates NET production by isolated human neutrophils (Chan et al., 2020). Furthermore, it is also thought that infection with $\mathrm{H} 5 \mathrm{~N} 1$ caused a more severe disease than H1N1 infection (Chan et al., 2020), which opens the question of whether there are other innate immune responses rather than NETs release that can account for more severe disease (Chan et al., 2020). The same study suggested that NET production induced by $\mathrm{H} 1 \mathrm{~N} 1$ is not dependent on the NOX-produced ROS (Chan et al., 2020). Consistent with this notion is the observation that neutrophils exposed to the NOX inhibitor diphenyleneiodonium (DPI) were able to produce NETs in response to an $\mathrm{H} 1 \mathrm{~N} 1$ challenge (Chan et al., 2020). Thus, as observed for some bacteria, such as $S$. aureus, the possibility that NET release occurs independently of ROS production is also described for viruses (Chan et al., 2020).

Human respiratory syncytial virus (hRSV) represents one of the most important causes of acute lower respiratory tract infection in young children and the elderly (Bohmwald et al., 2016; Canedo-Marroquín et al., 2017; Rey-Jurado and Kalergis, 2017; Carvajal et al., 2019). Regarding the neutrophil role during hRSV infection, it was shown that hRSV triggers NET release in human-derived neutrophils (Funchal et al., 2015; Cortjens et al., 2016; Muraro et al., 2018). Furthermore, NETs were observed in the airways and lungs of children with severe lower respiratory tract disease caused by hRSV (LRTD) (Cortjens et al., 2016). Furthermore, the extensive NET formation was associated with occluded airways of hRSV-infected calves, which may or not colocalize with viral antigens (Cortjens et al., 2016). These data suggest that NETs may or not trap viral particles, but their exacerbated formation during hRSV infection contributes to airway obstruction (Cortjens et al., 2016). Regarding the mechanism involved in such neutrophil response, it was shown that RSV induced the classical ROSdependent NETosis in which viral particles are entrapped by DNA frameworks coated with MPO and NE. Furthermore, RSVinduced NETosis is also mediated by PAD-4-dependent histone citrullination and signaling through the PI3K/AKT signaling pathway (Muraro et al., 2018).

It was recently shown that during SARS-CoV-2 infection, the quantity of NETs release, measured as DNA-MPO complex, was increased in plasma, tracheal aspirate, and lung autopsies tissues from COVID-19 patients (Veras et al., 2020). Interestingly, this study also showed that infective SARS-CoV-2 but not the inactivated virus increased the release of NETs by neutrophils in an MOI-dependent manner (Veras et al., 2020). Notably, the release of NET after the SARS-CoV-2 challenge was abrogated when isolated neutrophils were pre-treated with a neutralizing anti-hACE2 antibody ( $\alpha$ ACE2) (Veras et al., 2020). Furthermore, the NET release was also prevented if neutrophils were pretreated with the drug camostat, an inhibitor of the serine protease TMPRSS2 that blocks early interactions of SARS-CoV-2 S protein with the ACE2 receptor (Hoffmann et al., 2020). Furthermore, drugs also appear to inhibit viral replication as the viral load of neutrophils exposed to SARS-CoV-2 was reduced after $\alpha$ ACE2 or camostat treatment (Veras et al., 2020).

This study also highlights the contribution of viral replication to the release of NETs upon the interaction of neutrophils with SARS-CoV-2. Incubation of neutrophils with tenofovir disoproxil fumarate (TDF), an RNA polymerase inhibitor (Clososki et al., 2020), reduced the release of NETs in neutrophils derived from healthy donors exposed to SARS-CoV-2. In addition, coculture of SARS-CoV-2-activated neutrophils with epithelial cells promotes cell death in vitro, and this effect was prevented if DNAse was added in the culture medium (Veras et al., 2020). These data suggest an essential role for the extracellular DNA in promoting the cytotoxic effects of NETs. Together, these results underscore a possible detrimental role of NETs in the pathophysiology of COVID-19. Therefore, therapies targeted to inhibit the formation of NETs or promote the degradation of 
neutrophil extracellular DNA could be evaluated for a potential therapeutic benefit for COVID-19 (Veras et al., 2020).

Another study showed that high serum NETs, measured as cell-free DNA, DNA-MPO complex and citrullinated histones $\mathrm{H} 3$, are present in several hospitalized patients with COVID-19 (Zuo et al., 2020). The authors measure three different markers to assess the presence of NETs in blood corresponding to cellfree DNA, MPO-DNA, and Citrullinated Histone 3. Interestingly, sera from COVID-19 patients were a potent stimulator of NETs release when added to resting neutrophils, suggesting that a component present in serum may generate a pro-NETotic state on COVID-19 patients (Zuo et al., 2020).

It has also been described that those levels of plasma MPO-DNA complexes increased in intubated and dead COVID-19 patients (Middleton et al., 2020). The severity of the disease correlated directly with plasma MPO-DNA complexes. Soluble and cellular factors triggering NETs were significantly increased in COVID-19 patients. Furthermore, pulmonary autopsies showed NET-containing microthrombi with infiltrating neutrophils and platelets. Finally, neutrophils from COVID-19 patients displayed excessive NETs at baseline, and COVID-19 plasma triggered NET formation, blocked by neonatal NET-inhibitory factor (nNIF) (Middleton et al., 2020). Considering the prothrombotic clinical presentations of COVID-19 and the role of NETs in triggering such response points to targeting NETs as a novel therapeutic intervention for COVID-19 (Middleton et al., 2020).

Regarding additional pathways that regulate the generation of NETs during COVID-19, the pro-inflammatory cytokine IL-1 $\beta$ has been described as a critical inductor of NETs, both in vivo and in vitro assays (Meher et al., 2018). Furthermore, current evidence also suggests that NETs may promote the production of IL- $1 \beta$ precursors by macrophages that are used to amplify further the production of NETs (Hu et al., 2017). Under this scenario of excessive NET formation, alveolar and pulmonary endothelium becomes damaged, leading to the release of the von Willebrand factor (vWF), which activates blood platelets and neutrophils (Fernández-Pérez et al., 2021). Subsequently, activated platelets also stimulate neutrophils to produce NETs and clots, promoting airway obstruction impairing an efficient gaseous exchange (Pujhari et al., 2020).

IgA is another factor that can modulate NET formation during SARS-CoV-2 infection (Stacey et al., 2021). IgA is the second most abundant antibody present in the circulation and is enriched at mucosal surfaces. Therefore, this antibody plays a crucial role in protecting against mucosal pathogens, including viruses. IgA can also stimulate effector functions via the engagement of $\mathrm{Fc}$ alpha receptors (Fc- $\alpha \mathrm{RI}$ ) expressed on the surface of neutrophils (Stacey et al., 2021). In recent work, it was shown that IgA-virus immune complexes potentiate NETs release. This experiment used purified SARS-CoV-2 spike pseudotyped lentivirus, which were then opsonized with polyclonal IgA isolated from a convalescent COVID-19 donor serum. Interestingly virus opsonization increases the NET formation and potentiates a suicidal NETs release pathway. This process was independent of TLR signaling but required a functional NADPH oxidase complex. Therefore, targeting the
NADPH oxidase complex may be a suitable strategy to decrease SARS-CoV-2 triggered NETs release (Stacey et al., 2021).

\section{CONCLUDING REMARKS}

The mechanisms underlying NETs formation and their contribution to bacterial and viral infections have been studied as a primary function. However, during recent years, the role of NETs has changed, being an important matter when it comes to complications in several diseases. The different roles of NETs are in line with the fact that there is no specific pathway or stimuli to induce NETs release and that not all the stimuli are as good inducers of NETs as PMA or Gram-negative or -positive bacteria are. It is possible that the time of incubation and the dosing generates differences in the results obtained among the studies (Hoppenbrouwers et al., 2017). Also, as mentioned above, the antimicrobial properties of the granular enzymes of the NETs have been evaluated and, in some cases, do not generate a good antimicrobial capacity and probably have other immunomodulatory properties. Even more, the bactericidal capacities of NETs have been questioned because several studies have not evidenced a significant reduction of the initial inoculum in in vitro experiments (bactericidal effect). Further, the lysis (bacteriolytic effect) and the entrap of the bacteria (bacteriostatic effect) has not been consistently reproduced. In line with this, the citrullination of the DNA is also controversial because there are at least two more mechanisms, different from NETs release, that induce the citrullination: the leukotoxic hypercitrullination (LTH) which is not antimicrobial and can be induced by some virulence factors as toxins from S. aureus and Streptococcus spp., and the release of mitochondrial DNA due to a defect in mitophagy in neutrophils. Both processes are highly relevant in autoimmune disease such as rheumatoid arthritis and systemic lupus erythematosus, respectively (Konig and Andrade, 2016).

It is possible that the different types of NETs are induced at different time points during an infection, being possible that the first type of NETs release upon stimulation is composed of mitochondrial DNA, which still allows the survival of the cell. In this manner, the cell continues engulfing and performing antimicrobial properties. In addition, the release of mitochondrial DNA induces the secretion of type I interferon by plasmacytoid cells, generating a better immune response. Also, it is possible that NETs release composes of nuclear DNA occurs after the release of mitochondrial DNA, as an inflammatory consequence of the mitochondrial NETs release, inducing the NETosis process due to the nuclear NETs release. As example of this, the fibers that entrap the microorganisms are generated in vital NETs release, in opposite to the suicidal NETosis, were a cloud of DNA is generated, which not necessarily present antimicrobial properties (Yousefi and Simon, 2016).

It is currently studied that bacteria and viruses induce different pathways of NETs release, depending on the receptor activated by the microorganism. In this sense, bacteria have developed various mechanisms to evade the NETs release, generating a state of inflammation that allows pathogen spreading or the 
generation of a niche of infection-being the most common virulence factor among bacteria, the enzymes that degraded the NETs structure (Table 1). It is essential to mention that as NETs release, an inflammatory environment exists, and regulating this process is extremely necessary. One regulation occurs during the elimination of the NETs structure by the action of DNases, or C1q, allowing the recognition by the M1 macrophages (Farrera and Fadeel, 2013). Finally, it is crucial to find a proper definition of NETs due to the several aspects discussed above, which recognize if some pathogens induce or not the structure with antimicrobial properties or induce a structure that allows a higher inflammatory environment. Along these lines, this antimicrobial response will open targets for therapeutic intervention to treat diseases caused by bacteria and viruses, for example, the treatment of cystic fibrosis with DNases to liquify the sputum properly.

\section{REFERENCES}

Al-Anazi, K. A., Al-Anazi, W. K., and Al-Jasser, A. M. (2020). Neutrophils, NETs, NETosis and their paradoxical roles in COVID-19. J. Stem Cell Ther. Transplant. 4, 003-010. doi: 10.29328/journal.jsctt.1001020

Amini, P., Stojkov, D., Felser, A., Jackson, C. B., Courage, C., Schaller, A., et al. (2018). Neutrophil extracellular trap formation requires OPA1-dependent glycolytic ATP production. Nat. Commun. 9:2958. doi: 10.1038/s41467-01805387-y

Arai, Y., Nishinaka, Y., Arai, T., Morita, M., Mizugishi, K., Adachi, S., et al. (2014). Uric acid induces NADPH oxidase-independent neutrophil extracellular trap formation. Biochem. Biophys. Res. Commun. 443, 556-561. doi: 10.1016/j.bbrc. 2013.12.007

Arcos, J., Diangelo, L. E., Scordo, J. M., Sasindran, S. J., Moliva, J. I., Turner, J., et al. (2015). Lung mucosa lining fluid modification of Mycobacterium tuberculosis to reprogram human neutrophil killing mechanisms. J. Infect. Dis. 212, 948-958. doi: 10.1093/infdis/jiv146

Ashar, H. K., Mueller, N. C., Rudd, J. M., Snider, T. A., Achanta, M., Prasanthi, M., et al. (2018). The role of extracellular histones in influenza virus pathogenesis. Am. J. Pathol. 188, 135-148. doi: 10.1016/j.ajpath.2017.09.014

Aulik, N. A., Hellenbrand, K. M., and Czuprynski, C. J. (2012). Mannheimia haemolytica and its leukotoxin cause macrophage extracellular trap formation by bovine macrophages. Infect. Immun. 80, 1923-1933. doi: 10.1128/IAI.06 120-11

Azzouz, L., Cherry, A., Riedl, M., Khan, M., Pluthero, F. G., Kahr, W. H. A., et al. (2018). Relative antibacterial functions of complement and NETs: NETs trap and complement effectively kills bacteria. Mol. Immunol. 97, 71-81. doi: 10.1016/j.molimm.2018.02.019

Beiter, K., Wartha, F., Albiger, B., Normark, S., Zychlinsky, A., and HenriquesNormark, B. (2006). An endonuclease allows Streptococcus pneumoniae to escape from neutrophil extracellular traps. Curr. Biol. 16, 401-407. doi: 10.1016/ j.cub.2006.01.056

Berends, E. T. M., Horswill, A. R., Haste, N. M., Monestier, M., Nizet, V., and Von Köckritz-Blickwede, M. (2010). Nuclease expression by Staphylococcus aureus facilitates escape from neutrophil extracellular traps. J. Innate Immun. 2, 576-586. doi: 10.1159/000319909

Bhattacharya, M., Berends, E. T. M., Chan, R., Schwab, E., Roy, S., Sen, C. K., et al. (2018). Staphylococcus aureus biofilms release leukocidins to elicit extracellular trap formation and evade neutrophil-mediated killing. Proc. Natl. Acad. Sci. U.S.A. 115, 7416-7421. doi: 10.1073/pnas.1721949115

Birnberg-Weiss, F., Castillo, L. A., Pittaluga, J. R., Martire-Greco, D., Gómez, S. A., Landoni, V. I., et al. (2021). Modulation of neutrophil extracellular traps release by Klebsiella pneumoniae. J. Leukoc. Biol. 109, 245-256. doi: 10.1002/ JLB.4MA0620-099R

Birnie, E., Virk, H. S., Savelkoel, J., Spijker, R., Bertherat, E., Dance, D. A. B., et al. (2019). Global burden of melioidosis in 2015: a systematic review and

\section{AUTHOR CONTRIBUTIONS}

SB and BS: visualization. BS and OA: writing - origi nal draft. AK and SB: writing - review and editing. All authors contributed to the article and approved the submitted version.

\section{FUNDING}

This study was supported by grants "Fondo Nacional de Ciencia y Tecnología de Chile" (FONDECYT) (\# 1190830 and \# 11706964), the Millennium Institute on Immunology and Immunotherapy, ANID - Millennium Science Initiative Program ICN09_016 (former P09/016-F), and the Regional Government of Antofagasta through the Innovation Fund for Competitiveness FIC-R 2017 (BIP Code: 30488811-0).

data synthesis. Lancet Infect. Dis. 19, 892-902. doi: 10.1016/S1473-3099(19)30 $157-4$

Bohmwald, K., Espinoza, J. A., Rey-Jurado, E., Gómez, R. S., González, P. A., Bueno, S. M., et al. (2016). Human respiratory syncytial virus: infection and pathology. Semin. Respir. Crit. Care Med. 37, 522-537.

Bouabe, H., Liu, Y., Moser, M., Bösl, M. R., and Heesemann, J. (2011). Novel highly sensitive IL-10-b-lactamase reporter mouse reveals cells of the innate immune system as a substantial source of IL-10 in vivo. J. Immunol. 187, 3165-3176. doi: 10.4049/jimmunol.1101477

Bouchez, V., and Guiso, N. (2015). Bordetella pertussis, B. parapertussis, vaccines and cycles of whooping cough. Pathog. Dis. 73:ftv055. doi: 10.1093/femspd/ ftv055

Branzk, N., Lubojemska, A., Hardison, S. E., Wang, Q., Gutierrez, M. G., Brown, G. D., et al. (2014). Neutrophils sense microbe size and selectively release neutrophil extracellular traps in response to large pathogens. Nat. Immunol. 15, 1017-1025. doi: 10.1038/ni.2987

Brinkmann, V., Reichard, U., Goosmann, C., Fauler, B., Uhlemann, Y., Weiss, D. S., et al. (2004). Neutrophil extracellular traps kill bacteria. Science 303, 1532-1535.

Brown, G. T., and McIntyre, T. M. (2011). Lipopolysaccharide signaling without a nucleus: kinase cascades stimulate platelet shedding of proinflammatory IL$1 \beta$-rich microparticles. J. Immunol. 186, 5489-5496. doi: 10.4049/jimmunol. 1001623

Buchanan, J. T., Simpson, A. J., Aziz, R. K., Liu, G. Y., Kristian, S. A., Kotb, M., et al. (2006). DNase expression allows the pathogen group A Streptococcus to escape killing in neutrophil extracellular traps. Curr. Biol. 16, 396-400. doi: 10.1016/j.cub.2005.12.039

Cacciotto, C., Cubeddu, T., Addis, M. F., Anfossi, A. G., Tedde, V., Tore, G., et al. (2016). Mycoplasma lipoproteins are major determinants of neutrophil extracellular trap formation. Cell. Microbiol. 18, 1751-1762. doi: 10.1111/cmi. 12613

Campillo-Navarro, M., Leyva-Paredes, K., Donis-Maturano, L., GonzálezJiménez, M., Paredes-Vivas, Y., Cerbulo-Vázquez, A., et al. (2017). Listeria monocytogenes induces mast cell extracellular traps. Immunobiology 222, 432439. doi: 10.1016/j.imbio.2016.08.006

Campillo-Navarro, M., Leyva-Paredes, K., Donis-Maturano, L., Rodríguez-López, G. M., Soria-Castro, R., García-Pérez, B. E., et al. (2018). Mycobacterium tuberculosis catalase inhibits the formation of mast cell extracellular traps. Front. Immunol. 9:1161. doi: 10.3389/fimmu.2018.01161

Canedo-Marroquín, G., Acevedo-Acevedo, O., Rey-Jurado, E., Saavedra, J. M., Lay, M. K., Bueno, S. M., et al. (2017). Modulation of host immunity by human respiratory syncytial virus virulence factors: a synergic inhibition of both innate and adaptive immunity. Front. Cell. Infect. Microbiol. 7:367. doi: 10.3389/fcimb. 2017.00367

Carvajal, J. J., Avellaneda, A. M., Salazar-Ardiles, C., Maya, J. E., Kalergis, A. M., and Lay, M. K. (2019). Host components contributing to respiratory syncytial virus pathogenesis. Front. Immunol. 10:2152. doi: 10.3389/fimmu.2019.02152 
Castillo, L. A., Birnberg-Weiss, F., Rodriguez-Rodrigues, N., Martire-Greco, D., Bigi, F., Landoni, V. I., et al. (2019). Klebsiella pneumoniae ST258 negatively regulates the oxidative burst in human neutrophils. Front. Immunol. 10:929. doi: 10.3389/fimmu.2019.00929

Céspedes, P. F., Rey-Jurado, E., Espinoza, J. A., Rivera, C. A., Canedo-Marroquín, G., Bueno, S. M., et al. (2017). A single, low dose of a cGMP recombinant BCG vaccine elicits protective $\mathrm{T}$ cell immunity against the human respiratory syncytial virus infection and prevents lung pathology in mice. Vaccine 35, 757-766. doi: 10.1016/j.vaccine.2016.12.048

Chan, L. L. Y., Nicholls, J. M., Peiris, J. S. M., Lau, Y. L., Chan, M. C. W., and Chan, R. W. Y. (2020). Host DNA released by NETosis in neutrophils exposed to seasonal $\mathrm{H} 1 \mathrm{~N} 1$ and highly pathogenic H5N1 influenza viruses. Respir. Res. 21:160. doi: 10.1186/s12931-020-01425-w

Chanchamroen, S., Kewcharoenwong, C., Susaengrat, W., Ato, M., and Lertmemongkolchai, G. (2009). Human polymorphonuclear neutrophil responses to Burkholderia pseudomallei in healthy and diabetic subjects. Infect. Immun. 77, 456-463. doi: 10.1128/IAI.00 503-08

Chang, A., Khemlani, A., Kang, H., and Proft, T. (2011). Functional analysis of Streptococcus pyogenes nuclease A (SpnA), a novel group A streptococcal virulence factor. Mol. Microbiol. 79, 1629-1642. doi: 10.1111/j.1365-2958.2011. 07550.x

Chavakis, T., Wiechmann, K., Preissner, K. T., and Herrmann, M. (2005). Staphylococcus aureus interactions with the endothelium: the role of bacterial "secretable expanded repertoire adhesive molecules" (SERAM) in disturbing host defense systems. Thromb. Haemost. 94, 278-285. doi: 10.1160/TH05-050306

Chen, K., Nishi, H., Travers, R., Tsuboi, N., Martinod, K., Wagner, D. D., et al. (2012). Endocytosis of soluble immune complexes leads to their clearance by Fc $\gamma$ RIIIB but induces neutrophil extracellular traps via Fc $\gamma$ RIIA in vivo. Blood 120, 4421-4431.

Chen, K. W., Monteleone, M., Boucher, D., Sollberger, G., Ramnath, D., Condon, N. D., et al. (2018). Noncanonical inflammasome signaling elicits gasdermin D-dependent neutrophil extracellular traps. Sci. Immunol. 3:6676. doi: 10.1126/ sciimmunol.aar6676

Chow, O. A., Von Köckritz-Blickwede, M., Bright, A. T., Hensler, M. E., Zinkernagel, A. S., Cogen, A. L., et al. (2010). Statins enhance formation of phagocyte extracellular traps. Cell Host Microbe 8, 445-454. doi: 10.1016/j. chom.2010.10.005

Clancy, D. M. (2018). Extracellular neutrophil proteases are efficient regulators of IL-1, IL-33, and IL-36 cytokine activity but poor effectors of microbial killing. Cell Rep. 22, 2937-2950. doi: 10.1016/j.celrep.2018.02.062

Clark, S. R., Ma, A. C., Tavener, S. A., McDonald, B., Goodarzi, Z., Kelly, M. M., et al. (2007). Platelet TLR4 activates neutrophil extracellular traps to ensnare bacteria in septic blood. Nat. Med. 13, 463-469. doi: 10.1038/nm1565

Claudia, R., Rodrigo, D., Pablo, C., Susan, B., and Alexis, K. (2015). A recombinant Bacillus Calmette-Guérin (BCG) vaccine promotes protective humoral immunity against the human respiratory syncytial virus. Front. Immunol. 6:177. doi: 10.3389/conf.fimmu.2015.05. 00177

Clososki, G. C., Soldi, R. A., da Silva, R. M., Guaratini, T., Lopes, J. N. C., Pereira, P. R. R., et al. (2020). Tenofovir disoproxil fumarate: new chemical developments and encouraging in vitro biological results for SARS-CoV-2. J. Braz. Chem. Soc. 31, 1552-1556.

Cools-Lartigue, J., Spicer, J., Najmeh, S., and Ferri, L. (2014). Neutrophil extracellular traps in cancer progression. Cell. Mol. Life Sci. 71, 4179-4194.

Cortjens, B., de Boer, O. J., de Jong, R., Antonis, A. F., Sabogal Piñeros, Y. S., Lutter, R., et al. (2016). Neutrophil extracellular traps cause airway obstruction during respiratory syncytial virus disease. J. Pathol. 238, 401-411. doi: 10.1002/path. 4660

Covián, C., Fernández-Fierro, A., Retamal-Díaz, A., Díaz, F. E., Vasquez, A. E., Lay, M. K., et al. (2019). BCG-induced cross-protection and development of trained immunity: implication for vaccine design. Front. Immunol. 10:2806. doi: 10.3389/fimmu.2019.02806

Cunha, A. A., Porto, B. N., Nuñez, N. K., Souza, R. G., Vargas, M. H. M., Silveira, J. S., et al. (2014). Extracellular DNA traps in bronchoalveolar fluid from a murine eosinophilic pulmonary response. Allergy 69, 1696-1700. doi: 10.1111/ all. 12507
Davies, J. C. (2002). Pseudomonas aeruginosa in cystic fibrosis: pathogenesis and persistence. Paediatr. Respir. Rev. 3, 128-134. doi: 10.1016/s1526-0550(02) 00003-3

de Jong, H. K., Koh, G. C., Achouiti, A., van der Meer, A. J., Bulder, I., Stephan, F., et al. (2014). Neutrophil extracellular traps in the host defense against sepsis induced by Burkholderia pseudomallei (melioidosis). Intensive Care Med. Exp. 2:21. doi: 10.1186/s40635-014-0021-2

Deutscher, M., Lewis, M., Zell, E. R., Taylor, T. H. Jr., Van Beneden, C., and Schrag, S. (2011). Incidence and severity of invasive Streptococcus pneumoniae, Group A Streptococcus, and Group BS treptococcus infections among pregnant and postpartum women. Clin. Infect. Dis. 53, 114-123. doi: 10.1093/cid/cir325

Doster, R. S., Rogers, L. M., Gaddy, J. A., and Aronoff, D. M. (2018). Macrophage extracellular traps: a scoping review. J. Innate Immun. 10, 3-13. doi: 10.1159/ 000480373

Douda, D. N., Khan, M. A., Grasemann, H., and Palaniyar, N. (2015). SK3 channel and mitochondrial ROS mediate NADPH oxidase-independent NETosis induced by calcium influx. Proc. Natl. Acad. Sci. U.S.A. 112, 2817-2822. doi: 10.1073/pnas.1414055112

Dworski, R., Simon, H. U., Hoskins, A., and Yousefi, S. (2011). Eosinophil and neutrophil extracellular DNA traps in human allergic asthmatic airways. J. Allergy Clin. Immunol. 127, 1260-1266. doi: 10.1016/j.jaci.2010.12.1103

Eby, J. C., Gray, M. C., and Hewlett, E. L. (2014). Cyclic AMP-mediated suppression of neutrophil extracellular trap formation and apoptosis by the Bordetella pertussis adenylate cyclase toxin. Infect. Immun. 82, 5256-5269. doi: 10.1128/ IAI.02487-14

Echevarría, L. U., Leimgruber, C., González, J. G., Nevado, A., Álvarez, R., García, L. N., et al. (2017). Evidence of eosinophil extracellular trap cell death in copd: does it represent the trigger that switches on the disease? Int. J. COPD 12, 885-896. doi: 10.2147/COPD.S115969

Eisenbeis, J., Saffarzadeh, M., Peisker, H., Jung, P., Thewes, N., Preissner, K. T., et al. (2018). The Staphylococcus aureus extracellular adherence protein Eap Is a DNA binding protein capable of blocking neutrophil extracellular trap formation. Front. Cell. Infect. Microbiol. 8:235. doi: 10.3389/fcimb.2018.00235

Farrera, C., and Fadeel, B. (2013). Macrophage clearance of neutrophil extracellular traps is a silent process. J. Immunol. 191, 2647-2656. doi: 10.4049/jimmunol. 1300436

Fernández-Pérez, M. P., Águila, S., Reguilón-Gallego, L., Los Reyes-García, A. M., Miñano, A., Bravo-Pérez, C., et al. (2021). Neutrophil extracellular traps and von Willebrand factor are allies that negatively influence COVID-19 outcomes. Clin. Transl. Med. 11:e268. doi: 10.1002/ctm2.268

Francis, R. J., Butler, R. E., and Stewart, G. R. (2014). Mycobacterium tuberculosis ESAT-6 is a leukocidin causing Ca2+ influx, necrosis and neutrophil extracellular trap formation. Cell Death Dis. 5:e1474. doi: 10.1038/cddis. 2014.394

Fuchs, T. A., Abed, U., Goosmann, C., Hurwitz, R., Schulze, I., Wahn, V., et al. (2007). Novel cell death program leads to neutrophil extracellular traps. J. Cell Biol. 176, 231-241. doi: 10.1083/jcb.200606027

Funchal, G. A., Jaeger, N., Czepielewski, R. S., Machado, M. S., Muraro, S. P., Stein, R. T., et al. (2015). Respiratory syncytial virus fusion protein promotes TLR-4dependent neutrophil extracellular trap formation by human neutrophils. PLoS One 10:e0124082. doi: 10.1371/journal.pone.0124082

Garcia-Romo, G. S., Caielli, S., Vega, B., Connolly, J., Allantaz, F., Xu, Z., et al. (2011). Netting neutrophils are major inducers of type I IFN production in pediatric systemic lupus erythematosus. Sci. Transl. Med. 3:73ra20. doi: 10. 1126/scitranslmed.3001201

Gevaert, E., Zhang, N., Krysko, O., Lan, F., Holtappels, G., De Ruyck, N., et al. (2017). Extracellular eosinophilic traps in association with Staphylococcus aureus at the site of epithelial barrier defects in patients with severe airway inflammation. J. Allergy Clin. Immunol. 139, 1849.e6-1860.e6. doi: 10.1016/j. jaci.2017.01.019

González, L. A., Melo-González, F., Sebastián, V. P., Vallejos, O. P., Noguera, L. P., Suazo, I. D., et al. (2021). Characterization of the anti-inflammatory capacity of IL-10-producing neutrophils in response to infection. Front. Immunol. 12:638917. doi: 10.3389/fimmu.2021.638917

Gorgojo, J., Scharrig, E., Gómez, R. M., Harvill, E. T., and Rodríguez, M. E. (2017). Bordetella parapertussis circumvents neutrophil extracellular bactericidal mechanisms. PLoS One 12:e0169936. doi: 10.1371/journal.pone. 0169936 
Goulart, C., Rodriguez, D., Kanno, A. I., Lu, Y.-J., Malley, R., and Leite, L. C. C. (2017). Recombinant BCG expressing a PspA-PdT fusion protein protects mice against pneumococcal lethal challenge in a prime-boost strategy. Vaccine 35 , 1683-1691. doi: 10.1016/j.vaccine.2017.02.029

Gray, R. D. (2018). NETs in pneumonia: is just enough the right amount? Eur. Respir. J. 51:1800619. doi: 10.1183/13993003.00619-2018

Guh, A. Y., Bulens, S. N., Mu, Y., Jacob, J. T., Reno, J., Scott, J., et al. (2015). Epidemiology of carbapenem-resistant Enterobacteriaceae in 7 US Communities, 2012-2013. JAMA 314, 1479-1487.

Guichard, M.-J., Kinoo, D., Aubriot, A.-S., Bauwens, N., Gougué, J., Vermeulen, F., et al. (2018). Impact of PEGylation on the mucolytic activity of recombinant human deoxyribonuclease I in cystic fibrosis sputum. Clin. Sci. 132, 1439-1452. doi: 10.1042/CS20180315

Guiducci, E., Lemberg, C., Küng, N., Schraner, E., Theocharides, A. P. A., and LeibundGut-Landmann, S. (2018). Candida albicans-induced NETosis is independent of peptidylarginine deiminase 4. Front. Immunol. 9:1573. doi: 10.3389/fimmu.2018.01573

Guimarães-Costa, A. B., Nascimento, M. T. C., Froment, G. S., Soares, R. P. P., Morgado, F. N., Conceição-Silva, F., et al. (2009). Leishmania amazonensis promastigotes induce and are killed by neutrophil extracellular traps. Proc. Natl. Acad. Sci. U.S.A. 106, 6748-6753. doi: 10.1073/pnas.0900226106

Hakkim, A., Fuchs, T. A., Martinez, N. E., Hess, S., Prinz, H., Zychlinsky, A., et al. (2011). Activation of the Raf-MEK-ERK pathway is required for neutrophil extracellular trap formation. Nat. Chem. Biol. 7, 75-77. doi: 10.1038/ nchembio. 496

Halder, L. D., Abdelfatah, M. A., Jo, E. A. H., Jacobsen, I. D., Westermann, M., Beyersdorf, N., et al. (2017). Factor H binds to extracellular DNA traps released from human blood monocytes in response to Candida albicans. Front. Immunol. 7:671. doi: 10.3389/fimmu.2016.00671

Halverson, T. W. R., Wilton, M., Poon, K. K. H., Petri, B., and Lewenza, S. (2015). DNA is an antimicrobial component of neutrophil extracellular traps. PLoS Pathog. 11:e1004593. doi: 10.1371/journal.ppat.1004593

Hellenbrand, K. M., Forsythe, K. M., Rivera-Rivas, J. J., Czuprynski, C. J., and Aulik, N. A. (2013). Histophilus somni causes extracellular trap formation by bovine neutrophils and macrophages. Microb. Pathog. 54, 67-75. doi: 10.1016/j. micpath.2012.09.007

Herzog, S., Dach, F., de Buhr, N., Niemann, S., Schlagowski, J., Chaves-Moreno, D., et al. (2019). High nuclease activity of long persisting Staphylococcus aureus isolates within the airways of cystic fibrosis patients protects against NET-mediated killing. Front. Immunol. 10:2552. doi: 10.3389/fimmu.2019.0 2552

Hiroki, C. H., Toller-Kawahisa, J. E., Fumagalli, M. J., Colon, D. F., Figueiredo, L. T. M., Fonseca, B. A. L. D., et al. (2019). Neutrophil extracellular traps effectively control acute chikungunya virus infection. Front. Immunol. 10:3108. doi: 10.3389/fimmu.2019.03108

Hoffmann, M., Hofmann-Winkler, H., Smith, J. C., Krüger, N., Sørensen, L. K., Søgaard, O. S., et al. (2020). Camostat mesylate inhibits SARS-CoV-2 activation by TMPRSS2-related proteases and its metabolite GBPA exerts antiviral activity. bioRxiv [Preprint]. doi: 10.1101/2020.08.05.237651

Hoppenbrouwers, T., Autar, A. S. A., Sultan, A. R., Abraham, T. E., van Cappellen, W. A., Houtsmuller, A. B., et al. (2017). In vitro induction of NETosis: comprehensive live imaging comparison and systematic review. PLoS One 12:e0176472. doi: 10.1371/journal.pone.0176472

Hu, S. C. S., Yu, H. S., Yen, F. L., Lin, C. L., Chen, G. S., and Lan, C. C. E. (2016). Neutrophil extracellular trap formation is increased in psoriasis and induces human $\beta$-defensin-2 production in epidermal keratinocytes. Sci. Rep. 6, 1-14. doi: $10.1038 /$ srep31119

Hu, Z., Murakami, T., Tamura, H., Reich, J., Kuwahara-Arai, K., Iba, T., et al. (2017). Neutrophil extracellular traps induce IL-1 $\beta$ production by macrophages in combination with lipopolysaccharide. Int. J. Mol. Med. 39, 549-558. doi: 10.3892/ijmm.2017.2870

Iuliano, A. D., Roguski, K. M., Chang, H. H., Muscatello, D. J., Palekar, R., Tempia, S., et al. (2018). Estimates of global seasonal influenza-associated respiratory mortality: a modelling study. Lancet 391, 1285-1300. doi: 10.1016/S01406736(17)33293-2

Jabalameli, F., Mirsalehian, A., Khoramian, B., Aligholi, M., Khoramrooz, S. S., Asadollahi, P., et al. (2012). Evaluation of biofilm production and characterization of genes encoding type III secretion system among
Pseudomonas aeruginosa isolated from burn patients. Burns 38, 1192-1197. doi: 10.1016/j.burns.2012.07.030

Jenne, C. N., Wong, C. H. Y., Zemp, F. J., McDonald, B., Rahman, M. M., Forsyth, P. A., et al. (2013). Neutrophils recruited to sites of infection protect from virus challenge by releasing neutrophil extracellular traps. Cell Host Microbe 13, 169-180. doi: 10.1016/j.chom.2013.01.005

Kenny, E. F., Herzig, A., Krüger, R., Muth, A., Mondal, S., Thompson, P. R., et al. (2017). Diverse stimuli engage different neutrophil extracellular trap pathways. eLife 6:e24437. doi: 10.7554/eLife.24437

Keshari, R. S., Jyoti, A., Dubey, M., Kothari, N., Kohli, M., Bogra, J., et al. (2012). Cytokines induced neutrophil extracellular traps formation: implication for the inflammatory disease condition. PLoS One 7:e48111. doi: 10.1371/journal.pone. 0048111

Kessenbrock, K., Krumbholz, M., Schönermarck, U., Back, W., Gross, W. L., Werb, Z., et al. (2009). Netting neutrophils in autoimmune small-vessel vasculitis. Nat. Med. 15, 623-625. doi: 10.1038/nm.1959

Khandpur, R., Carmona-Rivera, C., Vivekanandan-Giri, A., Gizinski, A., Yalavarthi, S., Knight, J. S., et al. (2013). NETs are a source of citrullinated autoantigens and stimulate inflammatory responses in rheumatoid arthritis. Sci. Transl. Med. 5:178ra40. doi: 10.1126/scitranslmed.3005580

Knight, J. S., Carmona-Rivera, C., and Kaplan, M. J. (2012). Proteins derived from neutrophil extracellular traps may serve as self-antigens and mediate organ damage in autoimmune diseases. Front. Immunol. 3:380. doi: 10.3389/fimmu. 2012.00380

Konig, M. F., and Andrade, F. (2016). A critical reappraisal of neutrophil extracellular traps and NETosis mimics based on differential requirements for protein citrullination. Front. Immunol. 7:461. doi: 10.3389/fimmu.2016.00461

Kraemer, B. F., Campbell, R. A., Schwertz, H., Franks, Z. G., Vieira de Abreu, A., Grundler, K., et al. (2012). Bacteria differentially induce degradation of Bcl-xL, a survival protein, by human platelets. Blood 120, 5014-5020. doi: 10.1182/blood2012-04-420661

Krismer, B., Weidenmaier, C., Zipperer, A., and Peschel, A. (2017). The commensal lifestyle of Staphylococcus aureus and its interactions with the nasal microbiota. Nat. Rev. Microbiol. 15, 675-687. doi: 10.1038/nrmicro.2017.104

Ladant, D., and Ullmann, A. (1999). Bordetella pertussis adenylate cyclase: a toxin with multiple talents. Trends Microbiol. 7, 172-176. doi: 10.1016/s09348840(11)80849-2

Lappann, M., Danhof, S., Guenther, F., Olivares-Florez, S., Mordhorst, I. L., and Vogel, U. (2013). In vitro resistance mechanisms of Neisseria meningitidis against neutrophil extracellular traps. Mol. Microbiol. 89, 433-449.

Lauth, X., Von Köckritz-Blickwede, M., McNamara, C. W., Myskowski, S., Zinkernagel, A. S., Beall, B., et al. (2009). M1 protein allows group a streptococcal survival in phagocyte extracellular traps through cathelicidin inhibition. J. Innate Immun. 1, 202-214. doi: 10.1159/000203645

Li, P., Li, M., Lindberg, M. R., Kennett, M. J., Xiong, N., and Wang, Y. (2010). PAD4 is essential for antibacterial innate immunity mediated by neutrophil extracellular traps. J. Exp. Med. 207, 1853-1862. doi: 10.1084/jem.20100239

Limmathurotsakul, D., Wongratanacheewin, S., Teerawattanasook, N., Wongsuvan, G., Chaisuksant, S., Chetchotisakd, P., et al. (2010). Increasing incidence of human melioidosis in Northeast Thailand. Am. J. Trop. Med. Hyg. 82, 1113-1117. doi: 10.4269/ajtmh.2010.10-0038

Liu, K., Sun, E., Lei, M., Li, L., Gao, J., Nian, X., et al. (2019). BCG-induced formation of neutrophil extracellular traps play an important role in bladder cancer treatment. Clin. Immunol. 201, 4-14. doi: 10.1016/j.clim.2019.02.005

Liu, P., Wu, X., Liao, C., Liu, X., Du, J., Shi, H., et al. (2014). Escherichia coli and Candida albicans induced macrophage extracellular trap-like structures with limited microbicidal activity. PLoS One 9:e0090042. doi: 10.1371/journal.pone. 0090042

Lood, C., Arve, S., Ledbetter, J., and Elkon, K. B. (2017). TLR7/8 activation in neutrophils impairs immune complex phagocytosis through shedding of FcgRIIA. J. Exp. Med. 214, 2103-2119. doi: 10.1084/jem.20161512

Loureiro, A., Pais, C., and Sampaio, P. (2019). Relevance of macrophage extracellular traps in C. albicans killing. Front. Immunol. 10:2767. doi: 10.3389/ fimmu.2019.02767

Lun, X., Yang, W., Alain, T., Shi, Z.-Q., Muzik, H., Barrett, J. W., et al. (2005). Myxoma virus is a novel oncolytic virus with significant antitumor activity against experimental human gliomas. Cancer Res. 65, 9982-9990. doi: 10.1158/ 0008-5472.CAN-05-1201 
Malachowa, N., Kobayashi, S. D., Freedman, B., Dorward, D. W., and DeLeo, F. R. (2013). Staphylococcus aureus leukotoxin GH promotes formation of neutrophil extracellular traps. J. Immunol. 191, 6022-6029. doi: 10.4049/ jimmunol.1301821

Malawista, S. E., Smith, E. O., and Seibyl, J. P. (2006). Cryopreservable neutrophil surrogates: granule-poor, motile cytoplasts from polymorphonuclear leukocytes home to inflammatory lesions in vivo. Cell Motil. Cytoskeleton 63, 254-257. doi: $10.1002 / \mathrm{cm} .20120$

Malawista, S. E., Van Blaricom, G., and Breitenstein, M. G. (1989). Cryopreservable neutrophil surrogates. Stored cytoplasts from human polymorphonuclear leukocytes retain chemotactic, phagocytic, and microbicidal function. J. Clin. Invest. 83, 728-732. doi: 10.1172/JCI113939

Manzenreiter, R. (2012). Ultrastructural characterization of cystic fibrosis sputum using atomic force and scanning electron microscopy. J. Cyst. Fibros. 11, 84-92. doi: 10.1016/j.jcf.2011.09.008

Marks, M. I., Pai, C. H., and Lafleur, L. (2018). Yersinia enterocolitica gastroenteritis in children and their families. J. Pediatr. 96, 95-104. doi: 10.1201/ 9781351077804-9

Martinelli, S., Urosevic, M., Daryadel, A., Oberholzer, P. A., Baumann, C., Fey, M. F., et al. (2004). Induction of genes mediating interferon-dependent extracellular trap formation during neutrophil differentiation. J. Biol. Chem. 279, 44123-44132. doi: 10.1074/jbc.M40588 3200

Martinez, R., Sarisky, R. T., Weber, P. C., and Weller, S. K. (1996). Herpes simplex virus type 1 alkaline nuclease is required for efficient processing of viral DNA replication intermediates. J. Virol. 70, 2075-2085. doi: 10.1128/JVI.70.4.20752085.1996

McIlroy, D. J., Jarnicki, A. G., Au, G. G., Lott, N., Smith, D. W., Hansbro, P. M., et al. (2014). Mitochondrial DNA neutrophil extracellular traps are formed after trauma and subsequent surgery. J. Crit. Care 29, 1133.e1-1133.e5. doi: 10.1016/j.jcrc.2014.07.013

Meher, A. K., Spinosa, M., Davis, J. P., Pope, N., Laubach, V. E., Su, G., et al. (2018). Novel role of IL (Interleukin)-1 $\beta$ in neutrophil extracellular trap formation and abdominal aortic aneurysms. Arterioscler. Thromb. Vasc. Biol. 38, 843-853. doi: 10.1161/ATVBAHA.117.309897

Menegazzi, R., Decleva, E., and Dri, P. (2012). Killing by neutrophil extracellular traps: fact or folklore? Blood 119, 1214-1216. doi: 10.1182/blood-2011-07364604

Metzler, K. D., Goosmann, C., Lubojemska, A., Zychlinsky, A., and Papayannopoulos, V. (2014). Myeloperoxidase-containing complex regulates neutrophil elastase release and actin dynamics during NETosis. Cell Rep. 8, 883-896. doi: 10.1016/j.celrep.2014.06.044

Middleton, E. A., He, X.-Y., Denorme, F., Campbell, R. A., Ng, D., Salvatore, S. P., et al. (2020). Neutrophil extracellular traps contribute to immunothrombosis in COVID-19 acute respiratory distress syndrome. Blood 136, 1169-1179. doi: 10.1182/blood.2020007008

Mohanan, S., Horibata, S., McElwee, J. L., Dannenberg, A. J., and Coonrod, S. A. (2013). Identification of macrophage extracellular trap-like structures in mammary gland adipose tissue: a preliminary study. Front. Immunol. 4:67. doi: 10.3389/fimmu.2013.00067

Möllerherm, H., Neumann, A., Schilcher, K., Blodkamp, S., Zeitouni, N. E., Dersch, P., et al. (2015). Yersinia enterocolitica-mediated degradation of neutrophil extracellular traps (NETs). FEMS Microbiol. Lett. 362:fnv192. doi: 10.1093/ femsle/fnv192

Mónaco, A., Canales-Huerta, N., Jara-Wilde, J., Härtel, S., Chabalgoity, J. A., Moreno, M., et al. (2021). Typhimurium triggers extracellular traps release in murine macrophages. Front. Cell. Infect. Microbiol. 11:639768. doi: 10.3389/ fcimb.2021.639768

Mooi, F. R., van Loo, I. H. M., van Gent, M., He, Q., Bart, M. J., Heuvelman, K. J., et al. (2009). Bordetella pertussis strains with increased toxin production associated with pertussis resurgence. Emerg. Infect. Dis. 15, 1206-1213. doi: 10.3201/eid1508.081511

Moon, A. F., Krahn, J. M., Lu, X., Cuneo, M. J., and Pedersen, L. C. (2016). Structural characterization of the virulence factor Sdal nuclease from Streptococcus pyogenes. Nucleic Acids Res. 44, 3946-3957. doi: 10.1093/nar/ gkw143

Morshed, M., Hlushchuk, R., Simon, D., Walls, A. F., Obata-Ninomiya, K., Karasuyama, H., et al. (2014). NADPH oxidase-independent formation of extracellular DNA traps by basophils. J. Immunol. 192, 5314-5323. doi: 10.4049/ jimmunol.1303418

Morshed, M., Yousefi, S., Stöckle, C., Simon, H. U., and Simon, D. (2012). Thymic stromal lymphopoietin stimulates the formation of eosinophil extracellular traps. Allergy 67, 1127-1137. doi: 10.1111/j.1398-9995.2012.02868.x

Mukherjee, M., Lacy, P., and Ueki, S. (2018). Eosinophil extracellular traps and inflammatory pathologies-untangling the web! Front. Immunol. 9:2763. doi: 10.3389/fimmu.2018.02763

Muniz, V. S., Silva, J. C., Braga, Y. A. V., Melo, R. C. N., Ueki, S., Takeda, M., et al. (2018). Eosinophils release extracellular DNA traps in response to Aspergillus fumigatus. J. Allergy Clin. Immunol. 141, 571.e7-585.e7. doi: 10.1016/j.jaci.2017. 07.048

Muñoz-Caro, T., Silva, L. M. R., Ritter, C., Taubert, A., and Hermosilla, C. (2014). Besnoitia besnoiti tachyzoites induce monocyte extracellular trap formation. Parasitol. Res. 113, 4189-4197. doi: 10.1007/s00436-014-4094-3

Muraro, S. P., De Souza, G. F., Gallo, S. W., Da Silva, B. K., De Oliveira, S. D., Vinolo, M. A. R., et al. (2018). Respiratory Syncytial Virus induces the classical ROS-dependent NETosis through PAD-4 and necroptosis pathways activation. Sci. Rep. 8:14166. doi: 10.1038/s41598-018-32576-y

Naimie, A., Keller, A. E., Stover, C. K., and Lalitha, P. (2016). Association of biofilm formation, Psl exopolysaccharide expression, and clinical outcomes in Pseudomonas aeruginosa keratitis: analysis of isolates in the steroids for Corneal Ulcers Trial. JAMA Ophthalmol. 134, 383-389. doi: 10.1001/jamaophthalmol. 2015.5956

Nakazawa, D., Shida, H., Kusunoki, Y., Miyoshi, A., Nishio, S., Tomaru, U., et al. (2016). The responses of macrophages in interaction with neutrophils that undergo NETosis. J. Autoimmun. 67, 19-28. doi: 10.1016/j.jaut.2015.08.018

Naqvi, N., Ahuja, K., Selvapandiyan, A., Dey, R., Nakhasi, H., and Puri, N. (2017). Role of Mast Cells in clearance of Leishmania through extracellular trap formation. Sci. Rep. 7, 1-16. doi: 10.1038/s41598-017-12753-1

Nelson, G. E., Pondo, T., Toews, K.-A., Farley, M. M., Lindegren, M. L., Lynfield, R., et al. (2016). Epidemiology of invasive group A streptococcal infections in the United States, 2005-2012. Clin. Infect. Dis. 63, 478-486. doi: 10.1093/cid/ ciw248

Omokawa, A., Ueki, S., Kikuchi, Y., Takeda, M., Asano, M., Sato, K., et al. (2018). Mucus plugging in allergic bronchopulmonary aspergillosis: implication of the eosinophil DNA traps. Allergol. Int. 67, 280-282. doi: 10.1016/j.alit.2017.08.002

Papayannopoulos, V., Metzler, K. D., Hakkim, A., and Zychlinsky, A. (2010). Neutrophil elastase and myeloperoxidase regulate the formation of neutrophil extracellular traps. J. Cell Biol. 191, 677-691. doi: 10.1083/jcb.201006052

Papayannopoulos, V., and Zychlinsky, A. (2009). NETs: a new strategy for using old weapons. Trends Immunol. 30, 513-521. doi: 10.1016/j.it.2009.07.011

Peñaloza, H. F., Ahn, D., Schultz, B. M., Piña-Iturbe, A., González, L. A., and Bueno, S. M. (2020). L-arginine enhances intracellular killing of carbapenemresistant ST258 by murine neutrophils. Front. Cell. Infect. Microbiol. 10:571771. doi: $10.3389 /$ fcimb.2020.571771

Pilsczek, F. H., Salina, D., Poon, K. K. H., Fahey, C., Yipp, B. G., Sibley, C. D., et al. (2010). A novel mechanism of rapid nuclear neutrophil extracellular trap formation in response to Staphylococcus aureus. J. Immunol. 185, 7413-7425. doi: 10.4049/jimmunol.1000675

Podschun, R., and Ullmann, U. (1998). Klebsiella spp. as nosocomial pathogens: epidemiology, taxonomy, typing methods, and pathogenicity factors. Clin. Microbiol. Rev. 11, 589-603. doi: 10.1128/CMR.11.4.589

Pujhari, S., Paul, S., Ahluwalia, J., and Rasgon, J. L. (2020). Clotting disorder in severe acute respiratory syndrome coronavirus 2. Rev. Med. Virol. 31:e2177. doi: $10.1002 / \mathrm{rmv} .2177$

Queen, J., and Satchell, K. J. F. (2012). Neutrophils are essential for containment of Vibrio cholerae to the intestine during the proinflammatory phase of infection. Infect. Immun. 80, 2905-2913. doi: 10.1128/IAI.00356-12

Rada, B., Jendrysik, M. A., Pang, L., Hayes, C. P., Yoo, D.-G., Park, J. J., et al. (2013). Pyocyanin-enhanced neutrophil extracellular trap formation requires the NADPH oxidase. PLoS One 8:e54205. doi: 10.1371/journal.pone.0054205

Rahman, M. M., and McFadden, G. (2020). Oncolytic virotherapy with myxoma virus. J. Clin. Med. Res. 9:171. doi: 10.3390/jcm9010171

Ramazanzadeh, R., Roshani, D., Shakib, P., and Rouhi, S. (2015). Prevalence and occurrence rate of Mycobacterium tuberculosis Haarlem family multi-drug resistant in the worldwide population: a systematic review and meta-analysis. J. Res. Med. Sci. 20, 78-88. 
Razak, N. A., Elaskalani, O., and Metharom, P. (2017). Pancreatic cancer-induced neutrophil extracellular traps: a potential contributor to cancer-associated thrombosis. Int. J. Mol. Sci. 18:487. doi: 10.3390/ijms18030487

Reichel, M., Muñoz-Caro, T., Sanchez Contreras, G., Rubio García, A., Magdowski, G., Gärtner, U., et al. (2015). Harbour seal (Phoca vitulina) PMN and monocytes release extracellular traps to capture the apicomplexan parasite Toxoplasma gondii. Dev. Comp. Immunol. 50, 106-115. doi: 10.1016/j.dci.2015.02.002

Rey-Jurado, E., and Kalergis, A. M. (2017). Immunological features of respiratory syncytial virus-caused pneumonia-implications for vaccine design. Int. J. Mol. Sci. 18:556. doi: 10.3390/ijms18030556

Riyapa, D., Buddhisa, S., Korbsrisate, S., Cuccui, J., Wren, B. W., Stevens, M. P., et al. (2012). Neutrophil extracellular traps exhibit antibacterial activity against Burkholderia pseudomallei and are influenced by bacterial and host factors. Infect. Immun. 80, 3921-3929. doi: 10.1128/IAI.00806-12

Rochael, N. C., Guimarães-Costa, A. B., Nascimento, M. T. C., Desouza-Vieira, T. S., Oliveira, M. P., Garciae Souza, L. F., et al. (2015). Classical ROSdependent and early/rapid ROS-independent release of neutrophil extracellular traps triggered by Leishmania parasites. Sci. Rep. 5, 1-11. doi: 10.1038/srep1 8302

Rodrigues, D. A. S., Prestes, E. B., Gama, A. M. S., de Souza Silva, L., Pinheiro, A. A. S., Ribeiro, J. M. C., et al. (2020). CXCR4 and MIF are required for neutrophil extracellular trap release triggered by Plasmodium-infected erythrocytes. PLoS Pathog. 16:e1008230. doi: 10.1371/journal.ppat.1008230

Ryu, S., and Cowling, B. J. (2020). Human influenza epidemiology. Cold Spring Harb. Perspect. Med. 11:a038356. doi: 10.1101/cshperspect.a038356

Saitoh, T., Komano, J., Saitoh, Y., Misawa, T., Takahama, M., Kozaki, T., et al. (2012). Neutrophil extracellular traps mediate a host defense response to human immunodeficiency virus-1. Cell Host Microbe 12, 109-116. doi: 10.1016/j.chom. 2012.05.015

Saraswathi, P., and Beuerman, R. W. (2015). Corneal biofilms: from planktonic to microcolony formation in an experimental keratitis infection with Pseudomonas Aeruginosa. Ocul. Surf. 13, 331-345. doi: 10.1016/j.jtos.2015. 07.001

Scharrig, E., Carestia, A., Ferrer, M. F., Cédola, M., Pretre, G., Drut, R., et al. (2015). Neutrophil extracellular traps are involved in the innate immune response to infection with leptospira. PLoS Negl Trop Dis. 9:e0003927. doi: 10.1371/journal. pntd.0003927

Segal, A. W. (2005). How neutrophils kill microbes. Annu. Rev. Immunol. 23, 197-223. doi: 10.1146/annurev.immunol.23.021704.115653

Seper, A., Hosseinzadeh, A., Gorkiewicz, G., Lichtenegger, S., Roier, S., Leitner, D. R., et al. (2013). Vibrio cholerae evades neutrophil extracellular traps by the activity of two extracellular nucleases. PLoS Pathog. 9:e1003614. doi: 10.1371/ journal.ppat.1003614

Shen, F., Tang, X., Cheng, W., Wang, Y., Wang, C., Shi, X., et al. (2016). Fosfomycin enhances phagocyte-mediated killing of Staphylococcus aureus by extracellular traps and reactive oxygen species. Sci. Rep. 6, 1-15. doi: 10.1038/srep 19262

Simon, D., Hoesli, S., Roth, N., Staedler, S., Yousefi, S., and Simon, H. U. (2011). Eosinophil extracellular DNA traps in skin diseases. J. Allergy Clin. Immunol. 127, 194-199. doi: 10.1016/j.jaci.2010.11.002

Soto, J. A., Gálvez, N. M. S., Rivera, C. A., Palavecino, C. E., Céspedes, P. F., Rey-Jurado, E., et al. (2018). Recombinant BCG vaccines reduce Pneumoviruscaused airway pathology by inducing protective humoral immunity. Front. Immunol. 9:2875. doi: 10.3389/fimmu.2018.02875

Souza, P. S. S., Barbosa, L. V., Diniz, L. F. A., da Silva, G. S., Lopes, B. R. P., Souza, P. M. R., et al. (2018). Neutrophil extracellular traps possess anti-human respiratory syncytial virus activity: possible interaction with the viral $\mathrm{F}$ protein. Virus Res. 251, 68-77. doi: 10.1016/j.virusres.2018.04.001

Speziale, P., and Pietrocola, G. (2021). Staphylococcus aureus induces neutrophil extracellular traps (NETs) and neutralizes their bactericidal potential. Comput. Struct. Biotechnol. J. 19, 3451-3457. doi: 10.1016/j.csbj.2021.06.012

Stacey, H. D., Golubeva, D., Posca, A., Ang, J. C., Novakowski, K. E., Zahoor, M. A., et al. (2021). IgA potentiates NETosis in response to viral infection. bioRxiv [Preprint]. doi: 10.1101/2021.01.04.424830

Stevens, D. L. (1992). Invasive group A Streptococcus infections. Clin. Infect. Dis. $14,2-11$.

Stoikou, M., Grimolizzi, F., Giaglis, S., Schäfer, G., van Breda, S. V., Hoesli, I. M., et al. (2017). Gestational diabetes mellitus is associated with altered neutrophil activity. Front. Immunol. 8:702. doi: 10.3389/fimmu.2017. 00702
Storisteanu, D. M. L., Pocock, J. M., Cowburn, A. S., Juss, J. K., Nadesalingam, A., Nizet, V., et al. (2017). Evasion of neutrophil extracellular traps by respiratory pathogens. Am. J. Respir. Cell Mol. Biol. 56, 423-431. doi: 10.1165/rcmb.20160193PS

Sun, E., Liu, K., Lei, M., Wang, L., Nian, X., Li, L., et al. (2020). BCG induced neutrophil extracellular traps formation and its regulatory mechanism. Res. Square [Epub ahead of print]. doi: 10.21203/rs.2.15638/v2

Sur Chowdhury, C., Giaglis, S., Walker, U. A., Buser, A., Hahn, S., and Hasler, P. (2014). Enhanced neutrophil extracellular trap generation in rheumatoid arthritis: analysis of underlying signal transduction pathways and potential diagnostic utility. Arthritis Res. Ther. 16:R122. doi: 10.1186/ar4579

Teng, T. S., Ji, A. L., Ji, X. Y., and Li, Y. Z. (2017). Neutrophils and immunity: from bactericidal action to being conquered. J. Immunol. Res. 2017:9671604. doi: $10.1155 / 2017 / 9671604$

Thammavongsa, V., Missiakas, D. M., and Schneewind, O. (2013). Staphylococcus aureus degrades neutrophil extracellular traps to promote immune cell death. Science 342, 863-866. doi: 10.1126/science.1242255

Thanabalasuriar, A., Scott, B. N. V., Peiseler, M., Willson, M. E., Zeng, Z., Warrener, P., et al. (2019). Neutrophil extracellular traps confine Pseudomonas aeruginosa ocular biofilms and restrict brain invasion. Cell Host Microbe 25, 526.e4-536.e4. doi: 10.1016/j.chom.2019.02.007

Theodor, Z. (2013). The immune response to Mycobacterium tuberculosis infection in humans. Tuberculosis Curr. Issues Diagn. Manag. 12, 115-123. doi: 10.5772/ 54986

Thiam, H. R., Wong, S. L., Qiu, R., Kittisopikul, M., Vahabikashi, A., Goldman, A. E., et al. (2020). NETosis proceeds by cytoskeleton and endomembrane disassembly and PAD4-mediated chromatin decondensation and nuclear envelope rupture. Proc. Natl. Acad. Sci. U.S.A. 117, 7326-7337. doi: 10.1073/ pnas. 1909546117

Thomas, C. J., and Schroder, K. (2013). Pattern recognition receptor function in neutrophils. Trends Immunol. 34, 317-328. doi: 10.1016/j.it.2013.02.008

Toussaint, M., Jackson, D. J., Swieboda, D., Guedán, A., Tsourouktsoglou, T. D., Ching, Y. M., et al. (2017). Host DNA released by NETosis promotes rhinovirus-induced type-2 allergic asthma exacerbation. Nat. Med. 23, 681-691. doi: $10.1038 / \mathrm{nm} .4332$

Uchiyama, S., Döhrmann, S., Timmer, A. M., Dixit, N., Ghochani, M., Bhandari, T., et al. (2015). Streptolysin O rapidly impairs neutrophil oxidative burst and antibacterial responses to Group A Streptococcus. Front. Immunol. 6:581. doi: 10.3389/fimmu.2015.00581

Ueki, S., Konno, Y., Takeda, M., Moritoki, Y., Hirokawa, M., Matsuwaki, Y., et al. (2016). Eosinophil extracellular trap cell death-derived DNA traps: their presence in secretions and functional attributes. J. Allergy Clin. Immunol. 137, 258-267. doi: 10.1016/j.jaci.2015.04.041

Ueki, S., Melo, R. C. N., Ghiran, I., Spencer, L. A., Dvorak, A. M., and Weller, P. F. (2013). Eosinophil extracellular DNA trap cell death mediates lytic release of free secretion-competent eosinophil granules in humans. Blood 121, 20742083. doi: 10.1182/blood-2012-05-432088

Urban, C., Xiong, X., Sohn, K., Schröppel, K., Brunner, H., and Rupp, S. (2005). The moonlighting protein Tsalp is implicated in oxidative stress response and in cell wall biogenesis in Candida albicans. Mol. Microbiol. 57, 1318-1341. doi: 10.1111/j.1365-2958.2005.04771.x

Urban, C. F., Ermert, D., Schmid, M., Abu-Abed, U., Goosmann, C., Nacken, W., et al. (2009). Neutrophil extracellular traps contain calprotectin, a cytosolic protein complex involved in host defense against Candida albicans. PLoS Pathog. 5:e1000639. doi: 10.1371/journal.ppat.1000639

Veras, F. P., Pontelli, M. C., Silva, C. M., Toller-Kawahisa, J. E., de Lima, M., Nascimento, D. C., et al. (2020). SARS-CoV-2-triggered neutrophil extracellular traps mediate COVID-19 pathology. J. Exp. Med. 217:e20201129. doi: 10.1084/ jem.20201129

Von Köckritz-Blickwede, M., Goldmann, O., Thulin, P., Heinemann, K., NorrbyTeglund, A., Rohde, M., et al. (2008). Phagocytosis-independent antimicrobial activity of mast cells by means of extracellular trap formation. Blood 111, 3070-3080. doi: 10.1182/blood-2007-07-104018

Vorobjeva, N. (2020). Mitochondrial permeability transition pore is involved in oxidative burst and NETosis of human neutrophils. Biochim. Biophys. Acta Mol. Basis Dis. 1866:165664. doi: 10.1016/j.bbadis.2020.165664

Wahl, B., O’Brien, K. L., Greenbaum, A., Majumder, A., Liu, L., Chu, Y., et al. (2018). Burden of Streptococcus pneumoniae and Haemophilus influenzae type b disease in children in the era of conjugate vaccines: global, regional, and 
national estimates for 2000-15. Lancet Glob. Health 6, e744-e757. doi: 10.1016/ S2214-109X(18)30247-X

Wang, H., Li, T., Chen, S., Gu, Y., and Ye, S. (2015). Neutrophil extracellular trap mitochondrial DNA and its autoantibody in systemic lupus erythematosus and a proof-of-concept trial of metformin. Arthr. Rheumatol. 67, 3190-3200. doi: 10.1002/art.39296

Wang, H., Zhang, H., Wang, Y., Brown, Z. J., Xia, Y., Huang, Z., et al. (2021). Regulatory T-cell and neutrophil extracellular trap interaction contributes to carcinogenesis in non-alcoholic steatohepatitis. J. Hepatol. 75, 1271-1283. doi: 10.1016/j.jhep.2021.07.032

Wang, L., Zhou, X., Yin, Y., Mai, Y., Wang, D., and Zhang, X. (2018). Hyperglycemia induces neutrophil extracellular traps formation through an NADPH oxidase-dependent pathway in diabetic retinopathy. Front. Immunol. 9:3076. doi: 10.3389/fimmu.2018. 03076

Wartha, F., Beiter, K., Albiger, B., Fernebro, J., Zychlinsky, A., Normark, S., et al. (2007). Capsule and D-alanylated lipoteichoic acids protect Streptococcus pneumoniae against neutrophil extracellular traps. Cell. Microbiol. 9, 1162 1171. doi: 10.1111/j.1462-5822.2006.00857.x

Watanabe, M., and Nagai, M. (2004). Whooping cough due to Bordetella parapertussis: an unresolved problem. Expert Rev. Anti. Infect. Ther. 2, 447-454. doi: 10.1586/14787210.2.3.447

Webster, S. J., Daigneault, M., Bewley, M. A., Preston, J. A., Marriott, H. M., Walmsley, S. R., et al. (2010). Distinct cell death programs in monocytes regulate innate responses following challenge with common causes of invasive bacterial disease. J. Immunol. 185, 2968-2979. doi: 10.4049/jimmunol.100 0805

Wilton, M., Halverson, T. W. R., Charron-Mazenod, L., Parkins, M. D., and Lewenza, S. (2018). Secreted phosphatase and deoxyribonuclease are required by Pseudomonas aeruginosa to defend against neutrophil extracellular traps. Infect. Immun. 86, e403-e418. doi: 10.1128/IAI.00403-18

Wong, K. W., and Jacobs, W. R. (2013). Mycobacterium tuberculosis exploits human interferon $\gamma$ to stimulate macrophage extracellular trap formation and necrosis. J. Infect. Dis. 208, 109-119. doi: 10.1093/infdis/jit097

Wong, S. L., Demers, M., Martinod, K., Gallant, M., Wang, Y., Goldfine, A. B., et al. (2015). Diabetes primes neutrophils to undergo NETosis, which impairs wound healing. Nat. Med. 21, 815-819. doi: 10.1038/nm.3887

Xu, J., Zhang, X., Pelayo, R., Monestier, M., Ammollo, C. T., Semeraro, F., et al. (2009). Extracellular histones are major mediators of death in sepsis. Nat. Med. 15, 1318-1321. doi: 10.1038/nm.2053

Yagüe-Muñoz, A., Arnedo-Pena, A., Herrera-León, S., Meseguer-Ferrer, N., Vizcaíno-Batllés, A., Romeu-García, M. À, et al. (2019). Descriptive epidemiology of Yersinia enterocolitica infection in a high-incidence area over an 8-year period, 2006-2013. EDICS project. Enferm. Infecc. Microbiol. Clin. 37, 441-447. doi: 10.1016/j.eimc.2018.11.002
Yamamoto, T., Kida, Y., Sakamoto, Y., and Kuwano, K. (2017). Mpn491, a secreted nuclease of Mycoplasma pneumoniae, plays a critical role in evading killing by neutrophil extracellular traps. Cell. Microbiol. 19:e12666. doi: 10.1111/cmi. 12666

Yipp, B. G., Petri, B., Salina, D., Jenne, C. N., Scott, B. N. V., Zbytnuik, L. D., et al. (2012). Infection-induced NETosis is a dynamic process involving neutrophil multitasking in vivo. Nat. Med. 18, 1386-1393. doi: 10.1038/nm.2847

Yousefi, S., Gold, J. A., Andina, N., Lee, J. J., Kelly, A. M., Kozlowski, E., et al. (2008). Catapult-like release of mitochondrial DNA by eosinophils contributes to antibacterial defense. Nat. Med. 14, 949-953. doi: 10.1038/nm.1855

Yousefi, S., Mihalache, C., Kozlowski, E., Schmid, I., and Simon, H. U. (2009). Viable neutrophils release mitochondrial DNA to form neutrophil extracellular traps. Cell Death Diff. 16, 1438-1444. doi: 10.1038/cdd.2009.96

Yousefi, S., Morshed, M., Amini, P., Stojkov, D., Simon, D., Von Gunten, S., et al. (2015). Basophils exhibit antibacterial activity through extracellular trap formation. Allergy 70, 1184-1188. doi: 10.1111/all.12662

Yousefi, S., and Simon, H.-U. (2016). NETosis - does it really represent nature's "Suicide Bomber"? Front. Immunol. 7:328. doi: 10.3389/fimmu.2016.00328

Zhu, L., Kuang, Z., Wilson, B. A., and Lau, G. W. (2013). Competence-independent activity of pneumococcal enda mediates degradation of extracellular DNA and nets and is important for virulence. PLoS One 8:e70363. doi: 10.1371/journal. pone. 0070363

Zhu, L., Liu, L., Zhang, Y., Pu, L., Liu, J., Li, X., et al. (2018). High level of neutrophil extracellular traps correlates with poor prognosis of severe influenza a infection. J. Infect. Dis. 217, 428-437. doi: 10.1093/infdis/jix475

Zuo, Y., Yalavarthi, S., Shi, H., Gockman, K., Zuo, M., Madison, J. A., et al. (2020). Neutrophil extracellular traps in COVID-19. JCI Insight 5:e138999. doi: 10.1172/jci.insight.138999

Conflict of Interest: The authors declare that the research was conducted in the absence of any commercial or financial relationships that could be construed as a potential conflict of interest.

Publisher's Note: All claims expressed in this article are solely those of the authors and do not necessarily represent those of their affiliated organizations, or those of the publisher, the editors and the reviewers. Any product that may be evaluated in this article, or claim that may be made by its manufacturer, is not guaranteed or endorsed by the publisher.

Copyright (C) 2022 Schultz, Acevedo, Kalergis and Bueno. This is an open-access article distributed under the terms of the Creative Commons Attribution License (CC BY). The use, distribution or reproduction in other forums is permitted, provided the original author(s) and the copyright owner(s) are credited and that the original publication in this journal is cited, in accordance with accepted academic practice. No use, distribution or reproduction is permitted which does not comply with these terms. 